\title{
Introduction to the zeolite structure-directing phenomenon by organic species: General as- pects
}

\author{
Luis Gómez-Hortigüela ${ }^{a, *}$ and Miguel Á. Camblor ${ }^{b, *}$
}

Abstract During the last years, a tremendous progress has been achieved in the application of new zeolite materials in many different sectors through different pioneering innovations in the field of zeolite synthesis. At the very core of the production of these new zeolite materials lies the use of organic species as structuredirecting agents (SDA), which has been recognized as the most important factor to determine the zeolite product rendered after the crystallization process. These organic species organize the inorganic zeolitic units and drives the crystallization pathway towards the production of particular zeolite framework types. This structure-direction phenomenon frequently works in combination with several other factors related to the chemical composition of the synthesis gels, mainly use of fluoride, concentration $\left(\mathrm{H}_{2} \mathrm{O} / \mathrm{T}\right.$ ratio) and presence of different heteroatoms, which are also relevant for the crystallization of particular zeolite materials. Several properties determine the structure-directing effect of these organic species, especially their molecular size and shape, hydrophobicity, rigidity $v s$ flexibility, and hydrothermal stability. The properties of the zeolitic materials synthesized can be tuned up to a certain point through the use of rationally-selected organic species with particular physico-chemical features as SDA. In this introductory chapter, we briefly review the history of the use of organic cations as SDAs, and give the fundaments of the different aspects related to this structure-direction phenomenon and factors affecting it, explaining the main properties of SDAs, providing some examples of recent uses and trends of organic SDAs, as well as the host-guest chemistry involved. In addition, we pay particular attention to the use of imidazoliumbased organic cations as SDAs because of their current relevance in the synthesis of new zeolite materials.

${ }^{a}$ Instituto de Catálisis y Petroleoquímica (ICP-CSIC) C/ Marie Curie 2, 28049Madrid. Spain. ${ }^{*}$ E-mail: lhortiguela@icp.csic.es

${ }^{b}$ Instituto de Ciencia de Materiales de Madrid (ICMM-CSIC) C/ Sor Juana Inés de la Cruz 3, 28049-Madrid. Spain.*E-mail: macamblor@icmm.csic.es

Keywords zeolites, templates, structure-directing agents, host-guest, imidazolium. 


\section{Introduction: Use of organic cations in the synthesis of zeolites}

Zeolites are an important class of inorganic microporous crystalline materials whose oxide-based network is composed of corner-sharing $\mathrm{TO}_{4}$ atoms, where $\mathrm{T}$ refers to a tetrahedral atom, most commonly Si and Al. Since their discovery, zeolites have found widespread applications in many different areas, especially in catalysis, adsorption/separation and ion-exchange processes [1]. Apart from these traditional uses of zeolites that have met a tremendous economic impact on different sectors of the chemical industry, remarkably on the petrochemical sector, new uses of zeolitic materials are emerging in the last years in different applications such as in luminescence, electricity, magnetism, medicine, microelectronics, etc [2]. Such a wide range of applications in very different processes is directly associated to the particular characteristics of these materials: i) Their unique microporous structure, with porous systems of channels and/or cavities of molecular dimensions which allow them to behave as molecular sieves or as shape-selective catalysts, and ii) their versatile range of compositions of the oxide networks that can build up the different frameworks, most commonly $\mathrm{Si}$ and $\mathrm{Al}$, but also extended to a large variety of other tetrahedral atoms such as B, Ge, P, Ga, etc. The oxide composition determines in a large extent important properties of the zeolite, like concentration, nature and strength of catalytic sites and polar (hydrophilic/hydrophobic) character of the channel surface. Therefore, a careful control of these two characteristics of zeolite materials, their porous network and their chemical composition, is fundamental in order to optimize their application in many different processes.

Zeolites are found as minerals in nature. Barrer pioneered in the late 1940's the study of the synthesis of zeolite materials in the laboratory by transformation of mineral phases in the presence of different salts at very high temperatures [3]. However, the fundamental breakthrough in the field was achieved by Milton, who departed from Barrer's mineralogical approach by using more reactive gels under softer conditions [4], which afforded in the late 1940's and early 1950's the discovery of over a dozen of new zeolites, including zeolites A and X [5], which rapidly met an amazing commercial success [6]. A subsequent fundamental milestone for the production of synthetic zeolites was provided in 1961 by Barrer and Denny [7], and by Kerr and Kokotailo [8], who first reported the use of organic ammonium cations in the synthesis of zeolites. The former reported the synthesis of several already known zeolites, including A and X, while the latter reported zeolite ZK4, a silica-rich version of zeolite A [9]. So far, synthetic zeolites prepared in the presence of inorganic cations were rich in $\mathrm{Al}$ because of the necessity of chargebalancing the abundant presence of inorganic cations. However, due to their smaller charge-to-volume ratio (because of their larger size), the introduction of organic cations enabled the synthesis of zeolites with lower amounts of $\mathrm{Al}$; this represented a significant discovery since high $\mathrm{Si} / \mathrm{Al}$ ratios (higher than 10 ) in zeolites provide a high hydrothermal stability and strong Brønsted acidity. The successful introduction of tetramethylammonium in the synthesis of zeolites soon triggered the use of other larger tetraalkylammonium cations which were soluble 
in the aqueous hydrothermal synthesis media. The use of tetraethylammonium by Mobil researchers led to the discovery in 1967 of the first high-silica zeolite, the key zeolite beta (BEA), by Wadlinger, Kerr and Rosinsky, with Si/Al ratios between 5 and 100 [10]. Soon after that, ZSM-5, another decisive zeolite for the chemical industry, was discovered in 1972 by using tetrapropylammonium [11], while a further increase in the number of carbons of the alkyl substituent to four (tetrabutylammonium) led to ZSM-11 [12]; both were multidimensional zeolites that reflected the branched structure of the organic cations used. ZSM-5 and Beta zeolites prepared by Mobil researchers represent two of the most successful acid zeolites used nowadays as industrial catalysts. On the other hand, Kerr opened up the possibility of using cyclic and more complex organic ammonium compounds (instead of tetraalkylammonium cations) in the synthesis of zeolites, with his synthesis of ZK-5 by using the dimethylammonium derivative of 1,4diazabicyclo[2,2,2]-octane, which then became a typical building block for organic ammonium cations [13]. Years later, the addition of organic amines (rather than quaternary ammonium cations) to aluminophosphate gels led to the discovery of another important class of zeolitic materials, the aluminophosphate $\left(\mathrm{AlPO}_{4}\right)$ family, by Wilson et al $[14,15]$. This involved not only the discovery of new framework topologies (some with no counterpart among zeolites), but also a major departure in the framework composition from the typical aluminosilicate network to a more hydrophilic aluminophosphate network.

All these new zeolite materials occluded the organic cations within their porous networks, which led to the idea that the organic cations templated in some way the synthesis of those frameworks, with the organic species directing the crystallization towards specific zeolites [16,17]; as quoted from reference 16, "templating is the phenomenon occurring during either the gelation or the nucleation process whereby the organic molecule organizes oxide tetrahedra into a particular geometric topology around itself and thus provides the initial building block for a particular structure type". In this context, the authors argued that the incorporation of an organic cation resulted in a specific chemical environment which could affect and determine the nucleation process, and in turn, the crystallization of a particular zeolite framework. Currently, organic species used in the synthesis of zeolites tend to be more loosely termed as structure-directing agents (SDA).

Since then, the addition of organic molecules to the synthesis gels of zeolite materials has led to a great number of discoveries of new zeolite materials, both in terms of new (usually more hydrophobic silica-based) compositions and, especially, of new zeolite topologies [18,19]. A wide variety of typical organic chemical reactions has been applied to produce new and increasingly more complex organic SDAs [20], such as Diels-Alder reactions [21], Michael additions [22], enamine chemistry [23], etc, many of which have led to new frameworks. In this introductory chapter, we will deal with general aspects of the structure-directing phenomenon, including the properties that organic species should fulfill to efficiently promote the crystallization of particular zeolite frameworks (section 2), factors (not intrinsically related to the organic species) that influence or even determine the structure-directing phenomenon (section 3) and the host-guest chemistry that gov- 
erns the interaction between the nascent zeolite frameworks and the organic species encapsulated (section 4). Finally, due to their current relevance, a special section will be devoted to the use of imidazolium-based SDAs in the synthesis of new zeolite materials (section 5). This chapter will explain the fundaments of structuredirection together with examples of the most recent research trends on each particular aspect of this phenomenon. Subsequent chapters in this Volume will then deal with specific types of species and tools to study the structure-directing phenomenon.

\section{Properties of organic structure-directing agents}

Throughout the years, the use of organic species to control the zeolite crystallization has permitted the synthesis of a large number of new zeolite structures with unique framework topologies and chemical compositions that have produced a tremendous impact on the chemical industry as acid catalysts [24,25], and as adsorbents in separation and purification processes [6]. As previously mentioned, the role of these organic cations during the synthesis of zeolites has been proposed as i) template effect, to account for the fact that a certain structural relationship between the molecular size and shape of the SDA and that of the zeolite framework that crystallizes is observed, with such relationship occurring during the formation of the zeolite nuclei [16], ii) structure-directing effect, term related to the fact that the addition of these organic species leads to the crystallization of a particular framework type that would not be produced in its absence, and iii) pore-filling ef$f e c t$, in the sense that the organic SDAs end up encapsulated within the porous zeolite structure and provide stability to the open zeolite framework through the development of non-bonded host-guest interactions, as will be explained more in detail in section 4 . In any case, all these three effects occur at the same time with more or less definition during the structure-directing phenomenon by organic species [26], although sometimes these terms have been distinctly used to emphasize particular roles of the organic species during the structure-directing phenomenon [27]. Several properties of the organic SDAs strongly affect its structure-direction performance and the chemical and structural properties of the zeolite framework crystallized, including their size and shape, their hydrophobic/hydrophilic nature, their hydrothermal stability, and their rigidity/flexibility with the consequent possibility of a large conformational space. All these properties will in combination determine the ability of an organic species to direct more or less specifically the synthesis of a particular framework type with a characteristic porous topology.

\subsection{Size and shape}

The original use of tetramethylammonium cations as SDAs led to small cavities (like the sodalite spherical cavity) with a size related to that of the guest species hosted within, which represented a first indication about the relationship be- 
tween the size and shape of the organic SDA and that of the void volume of the zeolite that hosts it. However, there is not always a straightforward relationship between both. For instance, this is evidenced by the fact that tetraethylammonium (TEA) led to the discovery of zeolite beta, with a high void volume and 12-MR 3 dimensional channels, while larger tetrapropylammonium (TPA) and tetrabutylammonium (TBA) led to zeolites based on 10-MR channels, ZSM-5 and ZSM11 , respectively. The reason for this unexpected behavior of the relatively small TEA cations directing the formation of the very open-framework of zeolite beta was later discovered to be related to a clustering mode of action of TEA cations during structure-direction of zeolite beta: Up to six TEA cations are clustered together in the channel intersections of the BEA framework [28]. This observation indicates that packing effects, i.e. how several organic cations pack and fit among each other when occluded in porous systems, can also affect the nature of the framework that crystallizes; this is particularly important in frameworks based on channels (rather than cages) microporous systems.

Small quaternary ammonium cations tend to give clathrasil structures, with cavities linked by small windows through which the guest species cannot diffuse (hence they are considered as 0-dimensional pore systems) [18]. As soon as the size of the organic species is enlarged (at least in one direction), zeolite frameworks based on channel systems start to crystallize. Zones and coworkers found that the number of clathrasil structures crystallized with organic cations reduced dramatically while simultaneously increasing the number of open zeolite frameworks produced when the $\mathrm{C} / \mathrm{N}$ ratio of the SDAs increased beyond 9 (see Figure 3 in ref 29). This was of course due to the enlargement of the organic cations that could not fit any more in the small cavities of the clathrasil structures and required larger cavities or channels to accommodate. During the structure-direction of cage-based zeolite frameworks, where packing effects are generally not important since usually only one organic cation sites within the cavities, the influence of an increase in size of the organic SDA is clearly apparent, and results in the formation of larger cavities. This can be clearly appreciated in Figure 1, where cagebased zeolites with cavities of increasing dimensions are produced upon an increase in size of the cyclic ammonium compound. It can be observed that not only the size of the molecules and that of the void space of the resulting hosting cavities are related, but also the shape of the organic SDA clearly determines the shape of the resulting cavity. Indeed, the preferred SDA cations for the synthesis of small-pore zeolites with large cavities, materials that are important as catalysts for the methanol-to-olefin process, involve cyclic or polycyclic ammonium cations that can be hosted in such cavities and stabilize them.

This relationship between size and shape is also apparent when considering zeolite frameworks based on channel (rather than cage) systems; however, as previously mentioned, in this case packing effects can sometimes lead to unexpected behaviors, like the crystallization of zeolite beta with a small cation like TEA. There is extensive evidence in the literature that an increase in size and rigidity of the organic SDAs has resulted in the crystallization of new zeolite frameworks with larger pores [30-33]. On the other hand, not only the size but also the shape of the organic cation has a profound impact on the channel system of the zeolite 
that crystallizes: linear cations tend to give zeolite frameworks based on onedimensional channels. An example of this is provided in Figure 2 (middle), where a large rigid and linear cation gives MTW, a zeolite system based on 12-MR onedimensional channels. In contrast, branched organic cations usually lead to multipore channel systems, with each molecular branch occupying different channels. The classical example of this is the structure-direction of tetrapropylammonium (TPA) cations towards the formation of ZSM-5 (MFI), where each of the four propyl chains site on a channel, two on the sinusoidal ones and two on the straight ones, clearly showing the relationship between the SDA molecular shape and that of the hosting zeolite framework (see Figure 2-top). In this context, recent studies have shown that a combination of a rational design of both the molecular size (adjusted to the channel size, with alkyl linear chains being optimum for 10-MR channels and cyclic ammonium cations for 12-MR channels) and the molecular shape (with four large substituents that site in the channel intersections with each molecular branch located on a channel) have allowed the discovery of new multipore-zeolites with 12-MR and 10-MR channel systems [34-36]. This concept is illustrated in Figure 2: The SDA used for the discovery of ITQ-39 (ITN) was based on a polycyclic rigid unit which typically directs the formation of one-dimensional 12-MR channels (like MTW, see Figure 2-middle) and on quaternary N atoms with propyl substituents which typically sites on channel intersections (like TPA in MFI zeolite, see Figure 2-top) with propyl branches directing 10-MR channels, thus resulting in the formation of a new multipore zeolite system based on 10- and 12-MR channels. This multipore zeolites based on channels of different size can have important applications since they can enable a kind of molecular traffic control of reactants and products through the different channel systems [37]. This and many other examples available in the literature clearly evidence the geometrical relationship between the size and shape of the SDA species and those of the zeolite framework that crystallizes around [29,38-43].

The relevance of the molecular size and shape of the organic SDAs is nicely illustrated by the different structure-directing effect of distinct diastereoisomers (cis/trans, endo/exo, syn/anti, etc). For instance, Tsuji and coworkers showed that among the different diastereoisomers of 1-benzyl-1-methyl-4-(trimethylene)piperidinium (trans-trans, cis-cis or trans-cis piperidinium), only the trans-trans isomer was able to direct the formation of zeolite beta (BEA), while the cis-cis isomer led to ZSM-12 (MTW) in pure-silica preparations [44] (see Figure 3-top). In their extensive work on SDAs, Zones and coworkers have found several examples of diastereoselective structure-directing effects: For instance, the cis-isomer of N,N-diethyldecahydroquinolinium was selective for SSZ-48 (SFE) in borosilicate composition and SSZ-31 (STO) or SSZ-35 (STF) as aluminosilicates, while the pure trans-isomer gave a layered silicate in borosilicate composition and SSZ$36(\mathrm{RTH})$ or amorphous phase as aluminosilicates [39,45] (Figure 3-bottom-left). Another example was provided by García and coworkers, who showed that the $(1 S, 2 S)$ diastereoisomer of 2-hydroxymethyl-1-benzyl-1-methylpyrrolidinium cation directed the synthesis of the MTW framework, while the $(1 S, 2 R)$-isomer was not able to promote the formation of such framework [46] (Figure 3-bottom-right). Molecular simulations showed a better fit of the molecular shape of the former 
isomer within the 1-dimensional channels of the MTW framework, which explained the experimental observations.

A recent proposal to take advantage of the possible imprinting of the shape and size of the organic SDAs on zeolite frameworks was reported by Corma and coworkers. If it were possible to use an organic SDA that mimics the transition state of an interesting reaction, it could be presumed that the performance of the zeolite could possibly be maximized [47]. In this strategy, the systems of pores and/or cavities would be produced following the shape and chemical properties of a rationally-designed SDA that mimics the transition state of a particular reaction through a molecular-recognition pattern. Because of the structure-directing phenomenon and the relationship between SDAs and zeolite hosts, this synthetic strategy would yield zeolite materials that would stabilize the transition state of such pre-established reactions, hence providing very efficient catalysts for them. Although this proposal have so far not produced any new zeolite, several known materials have been found, in retrospect, to fulfill the SDA/TS relationship and they, indeed, resulted in an improved catalytic performance. Figure 4 gives an example of one of the reactions studied, the disproportionation of toluene to give xylenes, an important reaction in the petrochemical industry. In this reaction, the mechanism goes through a carbocation transition state with a size larger than those of reactants and products (Figure 4-top). Three different SDAs mimicking the structure of the TS were proposed, with 'SDA2' already known to give a zeolite material, ITQ-27 (IWV). When loaded with $\mathrm{Ni}$, this material presented a higher catalytic activity per acid site than the commercial ZSM-5-based catalyst, showing the effectiveness of this new strategy to get improved catalysts for particular reactions through the imprinting of SDA molecular features [47].

\subsection{Hydrophobicity/hydrophilicity}

Molecular size and shape of the organic SDA cations is essential in determining the type of microporous system that crystallizes. However, it is generally considered that for an organic cation to effectively direct the synthesis of zeolitic materials, it requires a particular hydrophobic/hydrophilic character. On the one hand, the synthesis of zeolite materials generally takes place in aqueous systems which favor the condensation reactions between the aluminosilicate (or other heteroatoms) species. As a consequence, in order to make contact with such aluminosilicate species through which the structure-direction phenomenon occurs, the organic cations need to be soluble in the aqueous medium, and as such they require certain hydrophilicity. On the other hand, zeolite networks, especially those based on silica-rich compositions, are considered to be rather hydrophobic; consequently, again for structure-direction phenomena to take place, a close contact between the organic and the aluminosilicate species is required. Therefore, organic species need also to have a certain hydrophobic character in order to promote such contact through development of hydrophobic interactions. Indeed, the mechanism proposed by Burkett and Davis for structure-direction by organic cations [48-50] in- 
volved i) a first formation of hydrophobic hydration spheres of water molecules surrounding the organic cations on the one hand and the inorganic oligomeric units on the other, and ii) a subsequent overlap of the hydrophobic hydration spheres of both organic and inorganic entities, with a consequent release of water molecules, which would be driven by the development of stabilizing hydrophobic interactions between the organic and inorganic species, and establishing a close contact between them whereby structure-direction will take place through an impression of the molecular size/shape of the SDA on the nascent zeolite nuclei. Hence, a moderate hydrophobic nature is considered best for getting efficient SDA species.

In this respect, a milestone study about the optimal hydrophobicity of organic species required for producing effective SDAs is the work by Zones, Kubota and coworkers [51]. The authors reported a simple method to estimate the hydrophobicity of an organic quaternary ammonium cation by measuring their partition (as an iodide salt) between water and chloroform. They associated such partition with their $\mathrm{C} / \mathrm{N}$ ratio as an indication of hydrophobicity and related it with their efficiency in producing zeolite materials. After studying a large series of quaternary ammonium cations with different molecular structure and size, the authors found that cations with $\mathrm{C} / \mathrm{N}$ ratios greater than 16 showed a large percentage of transfer to chloroform, while this decreased to almost zero as the $\mathrm{C} / \mathrm{N}$ ratio was reduced below 10. Interestingly, this $\mathrm{C} / \mathrm{N}$ range between 10 and 16 where a partial transfer to the organic phase is observed was coincident with the window where most of the organic cations which direct the crystallization of zeolite frameworks are found [51]. It was concluded that organic cations have to be moderately hydrophobic in order to act as efficient SDAs: Cations with $\mathrm{C} / \mathrm{N}$ ratios larger than 16 are too hydrophobic and consequently they will not be soluble enough in the aqueous medium, while cations with $\mathrm{C} / \mathrm{N}$ ratios smaller than 10 will be too hydrophilic and will establish very strong interactions with water molecules which will be difficult to replace with aluminosilicate species during nucleation. A moderate hydrophobicity (in practice a $\mathrm{C} / \mathrm{N}$ ratio between 10 and 16) will ensure the SDA to be soluble in water but not interact too strongly with water molecules, while providing a hydrophobic character that generates favorable interactions with silica species [42]. Of course this requirement of moderate hydrophobicity reduces the availability of quaternary ammonium cations to be used as SDAs; nevertheless, recent works show that replacement of $\mathrm{N}$ by other heteroatoms such as sulfur may enable the use of cations with larger $\mathrm{C} / \mathrm{S}$ ratios because of the higher polarity of $\mathrm{C}-\mathrm{S}$ bonds. This would give large and complex sulfonium compounds with large $\mathrm{C} / \mathrm{S}$ ratios soluble in water, which would be important for the production of extra-large-pore zeolites [52]. In addition, other species with different polarities have been used as SDAs, as macrocyclic ethers [53], metal complexes [54] or quaternary phosphonium ions [55], which will be discussed in subsequent chapters in this Volume.

Nevertheless, the proposed $\mathrm{C} / \mathrm{N}$ limiting ratios are not absolutely exclusive. On the larger $\mathrm{C} / \mathrm{N}$ side, another type of quaternary ammonium cations with different hydrophobic properties has been successfully used as SDA. Amphiphilic cations with a polar head of trimethylammonium and a long hydrophobic alkyl chain $\left(\mathrm{CH}_{3}\left(\mathrm{CH}_{2}\right)_{\mathrm{n}} \mathrm{N}\left(\mathrm{CH}_{3}\right)_{3}\right)^{+}$were very successful for the synthesis of mesoporous silica, 
acting as surfactants and inducing ordered micellar arrangements that were reproduced by the silica [56]. Moteki and coworkers have recently reported the synthesis of all-silica MFI zeolite by using cetyltrimethylammonium (CTA) as SDA (with a long-alkyl chain of $16 \mathrm{C}$ atoms), with a $\mathrm{C} / \mathrm{N}$ ratio of 19 and a low chargeto-volume ratio that resulted in MFI materials with low charge populations, where the CTA cations were proposed to site aligned with the straight channels (Figure 5-middle) [57]. The authors found that the chain length of the hydrophobic tail was critical for the crystallization of a particular framework: Cations with alkyl chains of 14 and 16 had similar lengths as that of two TPA cations along the straight channels (Figure 5-top). On the low $\mathrm{C} / \mathrm{N}$ side, additionally, the intermediate hydrophobicity concept requiring $\mathrm{C} / \mathrm{N}$ ratios between 10 and 16 is not hold in the case of the synthesis of pure silica zeolites using non-quaternary imidazoliumbased cations in fluoride media, where rather hydrophilic cations with C-to-charge ratios as low as 5 work well, as will be discussed in section 5 below.

An important breakthrough in the synthesis of zeolite materials was achieved by Ryoo and coworkers by using appropriately designed SDA cations with particular polarity properties [58]. The authors rationally designed bifunctional surfactants with a long hydrophobic alkyl chain with $22 \mathrm{C}$ atoms on one side and two quaternary ammonium groups linked by a C6 spacer on the other which roughly corresponded to the distance spanning two consecutive MFI unit cells along the ' $b$ ' axis. Each molecular side played different roles: The diammonium head groups acted as structure-directing species of the MFI framework while the long hydrophobic tails inhibited further crystal growth of the zeolite in the normal direction of the sheet by inducing the formation of a mesoscale micellar structure (Figure 5-bottom). The rational design of these SDAs with particular hydrophilic/hydrophobic properties allowed the synthesis of ultra thin ( $2 \mathrm{~nm}$ thick) zeolite materials which showed very promising catalytic activity due to a great suppression of the catalyst deactivation through coke deposition during methanol-togasoline conversion. By changing the head group, this strategy has been recently extended to other zeolite structures (BEA, MTW, MRE, MWW) $[59,60]$ as well as aluminophosphates (AEL, AEI, ATO) [61].

\subsection{Hydrothermal stability}

One of the main conditions that SDA species must fulfill is that they display a high hydrothermal stability in order for the organic cations to resist the harsh conditions imposed by the hydrothermal treatments, involving high temperatures and pressures in aqueous systems with usually basic pHs. In this context, quaternary ammonium cations frequently suffer the Hofmann elimination reaction (to give the corresponding alkenes and tertiary amines) when subjected to high $\mathrm{pHs}$ and high temperatures in aqueous media, and as a consequence SDA species can be degraded into fragments, thus canceling or at least altering their structure-directing mode of action.

In order to avoid this, the use of phosphonium cations as SDAs for the synthesis of zeolite materials has been recently introduced [55]. These cations do not suf- 
fer the Hofmann degradation, and as a consequence they enable the synthesis to be performed under more severe crystallization conditions. In fact, the use of these phosphonium cations has enabled the synthesis of new zeolite frameworks $[55,62]$. This will be explained more in detail in Chapter 3 in this Volume.

Degradation of the organic SDAs during the crystallization of zeolites may in occasions disturb the observed structure-direction not only as a result of the decreased concentration of the SDA, but also because of the possible formation of new organic species with a structure-directing ability of their own. An extreme case was recently published, where the starting N,N,N-trimethyl-tertbutylammonium (TMTBA) reacted with its own Hofmann degradation product (trimethylamine) yielding a smaller tetramethylammonium cation (TMA) [63]. Despite the largely different size and shape of the original and the newly produced cations, both have been shown to structure-direct the crystallization of AST zeolites in fluoride medium $[64,65]$. However, the unit cell sizes of the produced AST zeolites were largely different, resulting in their phase segregation. Quite amazingly, the initial crystallization of a TMTBA-containing AST zeolite was followed by its gradual and finally complete replacement by another AST zeolite with the same framework composition but containing the smaller TMA and displaying a smaller unit cell.

Degradation and rearrangement of organic cations to finally produce a smaller cation may be more frequent than thought. Other examples include: i) The degradation of certain diquats resulting in the crystallization of TMA-containing phases (AST, RUT and MTN [66] or Omega [67]); crystallization of TMA-containing AST when using the large N,N,N-trimethylbenzylammonium as SDA [68]; iii) cocrystallization of ITW together with MTW when using 1-benzyl-2,3dimethylimidazolium, obviously too large to fit into ITW cages, by degradation and rearrangement to produce 1,2,3-trimethylimidazolium [69]; iv) crystallization of CHA phases directed by 1,2-dimethylimidazolium formed by degradation of 1 alkyl-3-methylimidazolium cations during the ionothermal synthesis of aluminophosphates [70]; v) crystallization of TMA-containing MTN from Hofmann degradation and rearrangement of $(1 R, 2 S)$-dimethylephedrinium [71]; and vi) the use of unstable deep-eutectic mixtures as both solvent and SDA-delivering agent [72].

The stability of the SDA is also relevant because of the need to eliminate it from the zeolite prior to its use. Due to their usually large size, removal of these organics is typically performed by calcination at high temperature in air (or in ozone whose higher oxidizing power enables lower calcination temperatures); such high-temperature treatment and the simultaneous release of water can sometimes lead to a degradation of the zeolite framework. The difficult elimination of the SDAs together with the usually high cost of these organic species, which usually represent the most expensive components of a zeolite synthesis mixture, led Davis and coworkers to devise a new family of SDA species that have the ability to be degraded into simpler organic fragments within the zeolite structures. These fragments can then be easily extracted from the zeolite channels, avoiding the necessity of high-temperature calcination [73-75]. In addition, the extraction of these fragments would enable their recycle and reuse in subsequent synthesis after a reassembly into the original SDA, thus improving the cost-efficiency of zeolite syn- 
theses. One such type of organic species is represented by ketal-containing ammonium compounds, which are stable at the typical high $\mathrm{pHs}$ of zeolite synthesis (in alkaline medium), and can then be degraded into ketones and diols at low pHs after the crystallization process. As reported by the authors, this strategy performs best when used in combination with unspecific pore-filling agents easy to be extracted first, thus providing the void space required for $\mathrm{H}^{+}$to reach the degradable SDA cations.

\subsection{Rigidity vs flexibility}

Another crucial property which determines the mode of action of the organic cations during structure-direction of zeolite frameworks is the molecular rigidity/flexibility. Again this concept was nicely illustrated in the seminal work by $\mathrm{Ku}$ bota and coworkers [51], where they studied a large number of organic cations with different rigidities (expressed as the number of tertiary and quaternary connectivities in the molecular structure and the number or rings). The authors found that bulky and rigid cations containing one or more rings with limited conformational flexibility are best candidates for the crystallization of unique new largepore zeolite frameworks. Figure 6 (top) shows three examples of polycyclic rigid ammonium cations of increasing size that have led to zeolite frameworks of increasing pore dimensions [19]. There is generally a common agreement between zeolite researchers that rigid SDAs are more selective towards the formation of a particular framework type due to its restricted conformational variability. In contrast, flexible cations with a large number of methylene groups enable a wide conformational flexibility, and any of those conformations could in principle be hosted by different pore/cage systems of zeolite structures. Hence, flexible cations are usually considered as less selective SDAs since they can lead to different frameworks depending on the particular conformation; this can be considered a disadvantage since frequently mixture of phases are obtained. In contrast, such conformational variability brings a higher probability of finding appropriate crystallization conditions where they direct the formation of a zeolite material. This is illustrated by the use of hexamethonium cations for the synthesis of zeolite frameworks with very different framework densities and pore systems as a function of the synthesis conditions (mainly the Si/Ge ratio) [19] (Figure 6-bottom).

Flexibility in the SDA cations enables the occurrence of different conformers, each with a particular ability to promote the crystallization of zeolite frameworks. In this context, widely-studied is the case of tetraethylammonium cations which can adopt two different conformations: $t t . t t$, where the ethyl chains are more expanded, and tg.tg, where the ethyl chains are more clustered (Figure 7-top). The occurrence of both conformations can be easily monitored by Raman spectroscopy [76]. Indeed, O'Brien and coworkers found a different conformational behavior of tetraethylammonium (TEA) cations in the synthesis of microporous aluminophosphates as a function of the doping level of the gels: High doping levels (of $\mathrm{Zn}$ in this case) favored the tg.tg conformation and led to the crystallization of ZnAPO34 (CHA), while the lack of dopants promoted instead the $t$ t.tt conformer which 
led to AlPO-5 (AFI) (Figure 7-top) [77]. Ikuno and coworkers also studied the crystallization of zeolite beta in the presence of TEA, where the mode of structuredirection of these cations had been shown to occur as molecular clusters of up to 6 cations sited in the channel intersections. It was observed that the crystallization of zeolite beta required the TEA cation to adopt the $t$.tt conformation for the formation of viable nuclei, possibly because of a better packing of the clustered cations in the channel intersections [28]. Moreover, very recently Schmidt and coworkers have studied the template-framework interactions of TEA in different zeolite frameworks and related it to the conformation adopted by the SDA in the different structures [78]. They found that the conformation of the TEA cations depends not only on the framework geometry but also on the material composition. The authors found two regimes for the occlusion of the particular conformers: In frameworks where there is a high energy difference upon the confinement of the two conformations, only the most stable conformer is experimentally observed; in contrast, in frameworks where such energy difference is small, the occurrence of the different conformers depends on the composition of the network. A similar dependence on the presence of heteroatoms had been previously observed by Sánchez and coworkers for the crystallization of ZnAPSO-44 (CHA) in the presence of cyclohexylamine as SDA (Figure 7, bottom-left) [79]. By preparing materials with varying $\mathrm{Zn}$ and $\mathrm{Si}$ concentrations, the authors found that cyclohexylammonium in equatorial configuration was the only conformer found in materials where $\mathrm{Si}^{4+}$ (and/or $\mathrm{Zn}^{2+}$ ) was incorporated as isolated species, while the presence of $\mathrm{Si}$ islands (at high $\mathrm{Si}$ concentrations) involved the occlusion of axialcyclohexylammonium. This was ascribed to different hydrophilic/hydrophobic interactions as a function of the Si domains.

The high flexibility of certain SDAs has been proposed as a strategy for the discovery of new zeolites, if the conformation of the organics can be controlled, for instance, through the inorganic components of the synthesis mixture. The approach has been followed by Hong's group, after realizing that the pentamethonium diquat (i.e. N,N,N,N',N',N'-hexamethylpentanediammonium) can direct the crystallization of up to five different zeolites (EUO, *MRE, MTW, MWW and MOR) depending on the Al content and concentration of alkali cations, which results in a different conformation and host-guest interaction in each material [67]. When the flexible 1,4-bis(N-methylpyrrolidinium)butane (1,4-MPB) was used and the $\mathrm{Al}$ and $\mathrm{Na}^{+}$concentration were systematically varied, up to nine different zeolites were obtained [80]. Interestingly, this included, in a very narrow $\mathrm{Al}, \mathrm{Na}$ compositional window, the new zeolite TNU-9, a medium pore zeolite with a complex structure [81], as well as TNU-10, a high silica version of the natural zeolite stilbite [82].

Conformational flexibility has been found also relevant to determine the supramolecular chemistry associated to SDAs during structure direction. In a series of works, Gómez-Hortigüela and coworkers found a strongly different supramolecular behavior of two closely related diastereoisomers, $(1 R, 2 S)$-ephedrine and $(1 S, 2 S)$-pseudoephedrine, during the crystallization of AFI materials (Figure 7, bottom-right) $[83,84]$. Through a combination of fluorescence and molecular simulations, the authors observed that the $(1 R, 2 S)$-isomer showed a stronger trend to 
form supramolecular aggregates through $\pi-\pi$ stacking interactions in aqueous solution because of its particular most stable conformation with the alkyl chain in an extended configuration. In contrast, the $(1 S, 2 S)$-isomer showed a poorer supramolecular behavior because its different absolute configuration on $\mathrm{C} 1$ involved a distinct intramolecular chemistry driven by H-bond interactions, resulting in a stable conformation with the alkyl chain in a folded configuration which provoked a steric hindrance upon the approach of another molecule to form a supramolecular dimer. Again the presence of methylene units and a large conformational space can dramatically affect not only the selectivity of the structure-directing phenomenon but also its mode of action, having important implications in the zeolite materials rendered.

\section{Factors affecting the structure-directing phenomenon}

In section 2 we have explained the different physico-chemical properties of the organic SDA cations that determine their structure-direction efficiency and the zeolite product rendered. However, the outcome of a zeolite synthesis is not only affected by the organic cation used as SDA, but many other concomitant factors can alter the structure-direction phenomenon of a particular organic cation [85]. As a consequence, the use of a SDA in a zeolite synthesis does not necessarily lead to a unique zeolite framework where the host-guest interactions are maximized, but very often one single organic cation can lead to different zeolite materials depending on the synthesis conditions. The most common of these variables affecting the structure-directing phenomenon will be briefly explained in this section.

\subsection{Synthesis in fluoride media}

The synthesis of zeolite materials was traditionally performed at high $\mathrm{pH}$, usually higher than 10 , where the hydroxide anion may act as a mineralizer (i.e. a catalysts for the breaking and formation of $\mathrm{T}-\mathrm{O}$ bonds, $\mathrm{T}=\mathrm{Si}, \mathrm{Al}$, etc) favoring the dissolution of the silica and alumina as mobile species into the liquid phase, and allowing the condensation reactions to occur, hence enabling the crystallization process to proceed. However, Flanigen and coworkers first introduced the use of fluoride in the synthesis of zeolites to make pure silica MFI [86], and then systematic work by Guth and coworkers showed that fluoride anions can also play a mineralizing role during the synthesis of zeolites, replacing in this way the hydroxide anions and allowing the synthesis to be carried out at almost-neutral pHs [87-89]. The introduction of the fluoride route enabled a wide range of $\mathrm{pHs}$ to operate, affording the use of organic cations which are not stable at high $\mathrm{pHs}$ because of the Hofmann elimination reaction. Nonetheless, this synthetic route usually required higher SDA concentrations (generally $\mathrm{SDA} / \mathrm{SiO}_{2}$ ratio of 0.5 ).

Interestingly, this new synthesis method, which is particularly well suited for the synthesis of pure silica zeolites, renders zeolite materials with a very low con- 
centration of connectivity defects since fluoride is usually incorporated within the zeolite materials to charge-balance for the positive charge of the organic cations (instead of siloxy groups in high-silica zeolites prepared by the hydroxide route) [90]; hence, the absence of silanol/siloxy groups makes the resulting material rather hydrophobic [91], modifying its catalytic properties when chemical species of much different polarity are involved [92] and even opening new applications [93]. Additionally, fluoride has been proposed to play a structure-directing role [88], favoring the formation of double 4-rings (D4R), with fluoride usually siting within these cubic units, and hence leading frequently to frameworks rich in such units, as long as the overall zeolite topology can be directed by the organic SDA in question $[89,94]$. One argument in favour of such structure direction by fluoride is that pure or very high silica zeolites with D4R units have never been synthesized without using this anion during the crystallization. As shown by Zicovich-Wilson and coworkers, the effect is due to an ionization of the $\mathrm{Si}-\mathrm{O}$ bond induced by occluded fluoride, which causes an increase in the flexibility of the framework that decreases the strain associated to siliceous D4R units and make this kind of zeolites reachable for crystallization $[95,96]$.

\subsection{Effect of concentration (amount of water)}

The introduction of fluoride in the synthesis gels allowed for carrying out the zeolite synthesis at much higher concentrations (with very low amounts of water, reaching the reactant rather than solvent level). Synthesis in fluoride media were initially performed with the typical relative high water contents used in hydroxide media $\left(\mathrm{H}_{2} \mathrm{O} / \mathrm{SiO}_{2}\right.$ ratios between 30 and 60) [39]. Under these conditions mostly already known zeolites were synthesized. However, when Camblor and coworkers studied the use of highly concentrated gels for zeolite synthesis by the fluoride route (typically $\mathrm{H}_{2} \mathrm{O} / \mathrm{SiO}_{2}$ ratios below 15 and more typically below 7), a number of new zeolites was discovered. This work revealed an interesting trend in the synthesis of zeolite structures related to the amount of water content in the gel in the presence of fluoride [97]: Phases with lower framework densities are favored at lower water/silica ratios (higher concentration) under the same SDA species [98]. This experimental trend, which was later termed the Villaescusa rule, has served as a strategy for the synthesis of new open zeolites $[94,85]$. While other groups have also observed and confirmed the same trend [29,99-101], the Villaescusa rule still lacks a convincing explanation. The rule is clearly illustrated by the structuredirecting effect of trimethyladamantammonium, which yielded zeolite structures with very different pore volumes under different $\mathrm{H}_{2} \mathrm{O} / \mathrm{SiO}_{2}$ ratios: *STO at high water amounts $\left(\mathrm{H}_{2} \mathrm{O} / \mathrm{SiO}_{2}=15\right.$, with a pore volume of $0.11 \mathrm{~cm}^{3} / \mathrm{g}$ and a framework density of $\left.18.7 \mathrm{~T} / 1000 \AA^{3}\right)$, STT at intermediate ratios $\left(\mathrm{H}_{2} \mathrm{O} / \mathrm{SiO}_{2}=7.5\right.$, with a pore volume of $0.23 \mathrm{~cm}^{3} / \mathrm{g}$ and a framework density of $17.0 \mathrm{~T} / 1000 \AA^{3}$ ), and $\mathrm{CHA}$ at low water amounts $\left(\mathrm{H}_{2} \mathrm{O} / \mathrm{SiO}_{2}=3.0\right.$, with a pore volume of $0.32 \mathrm{~cm}^{3} / \mathrm{g}$ and a framework density of $15.1 \mathrm{~T} / 1000 \AA^{3}$ ) (see Figure 8) [98,99,102]. In fact, zeolite materials prepared at high concentrations typically give the highest fluoride and SDA uptakes. Therefore, the amount of water in the synthesis gel can clearly 
alter the structure-directing mode of action of a particular organic molecule, and has to be taken into account depending on the type of zeolite framework that is targeted.

\subsection{Lattice substitution: Presence of heteroatoms}

There exists many reviews on the effect of the introduction of heteroatoms (elements other than $\mathrm{Si}, \mathrm{Al}$ or $\mathrm{P}$ ) in tetrahedral positions of zeolite networks $[31,38]$, and it is beyond our intention to review this topic here. However, we want to at least mention it since the presence of these heteroatoms, such as $\mathrm{Ge}, \mathrm{Ga}, \mathrm{B}, \mathrm{Zn}, \mathrm{Be}$ and $\mathrm{Fe}$, can modify the structure-directing effect of the organic species towards certain zeolite frameworks by stabilizing particular building units. For instance, B, $\mathrm{Ga}$, Be and $\mathrm{Zn}$ may show some tendency to direct the formation of 3-rings, while Ge favors the formation of D4Rs and D3Rs. The isomorphic substitution of divalent or trivalent atoms by $\mathrm{Si}$ leads to negatively-charged networks which need to be balanced by the positive charge of the organic cations, and this can affect the incorporation of the SDA species and as a consequence their structure-directing mode of action. On the other hand, the optimum T-O bond lengths and T-O-T bond angles can be different for each $\mathrm{T}$ atom, and this can have an implication on the type of structural units that are preferred. For example, it is known that Si-O-B and $\mathrm{Si}-\mathrm{O}-\mathrm{Al}$ angles have a narrower range of variation in zeolite networks than $\mathrm{Si}$ $\mathrm{O}-\mathrm{Si}$ angles, and in fact those $\mathrm{Si}-\mathrm{O}-\mathrm{T}$ angles tend to be smaller than the corresponding Si-O-Si ones [103]. On the other hand, the incorporation of $\mathrm{Ge}$ in the synthesis gels together with the use of novel organic cations have led to a number of new zeolite structures, which very frequently display D4R units characteristic of Ge [38]. Typical Ge-O-Ge angles are smaller than their Si counterparts, and hence its presence can relax the geometric constraints imposed by the geometry of these particular structural units, in particular of D4Rs and D3Rs [30,31]. Again the presence of these particularly stable units can affect the structure-directing role of the organic cations towards particular framework types containing these units, as long as the overall framework can host the SDA species.

\section{Host/guest interactions during structure-direction}

The mode of structure-direction of the organic cations to direct the crystallization of particular framework types is driven by the development of host-guest interactions between both species during the nucleation and crystal-growth processes, which results in both kinetic and thermodynamic effects. From the kinetic side, these non-bonded (hydrophobic) interactions are responsible for the silica species to displace the hydrophobic hydration spheres around the organic cations and form the initial organo-inorganic precursors from which crystallization of a particular framework type will occur, as was discussed by Burket and Davis [48-50]. In fact, these interactions are crucial for the structure-direction phenomenon to occur and 
for the resultant geometric relationship between the size and shape of the organic cations and the void space of the zeolite framework which emerges. In this context, electrostatic interactions between the cationic SDAs and negatively-charged inorganic species are vital for keeping these organo-inorganic units assembled long enough for nucleation and crystal growth processes to occur [104]: Electrostatic interactions allow for SDA cations to be adsorbed on the surface of silica fragments and provide in this way a protective shielding of these intrinsically unstable silica units against hydrolysis [105].

The occlusion of SDA species in zeolite frameworks has also a crucial thermodynamic implication for the stabilization of zeolite materials. It is known that the intrinsic stability of silica-based polymorphs increases with the framework density: Quartz is the most stable polymorph of silica, and the stability is reduced when the porosity of the zeolite structure increases, as has been nicely shown by Piccione and coworkers from calorimetric studies [106,107]. From this point of view, it would be difficult to synthesize zeolite materials from thermodynamic arguments. However, porosity enables the incorporation of guest species, in this case the SDA cations, which may establish strong non-bonded interactions with the nascent zeolite frameworks, providing a relatively strong stabilization to the overall host-guest systems, making the formation of host-guest zeolite frameworks thermodynamically viable [26]. In any case, the energy differences observed in the thermodynamics of different zeolite host-guest systems suggest that the selfassembly process is dependent on a delicate interplay between a large number of weak interactions $[30,106]$, and sometimes it is difficult to predict which one will dominate the final outcome. In this line, Khan and coworkers have recently shown through Monte-Carlo modeling techniques that the strength of the host-guest interactions is crucial on the type of porous material that is directed: Very strong interactions (>1.2 kcal/mol SDA-oxygen contacts) would lead to 2-dimensional layered materials due to the higher optimization of host-guest attractions in open layered systems. Negligible host-guest interactions would also lead to 2dimensional materials, while 3-dimensional microporous zeolitic materials are only produced for a relatively narrow range of medium-strength interactions [108]. This might explain the frequent crystallization of low-dimensional AlPO frameworks in the presence of amines because of the abundant presence of very strong $\mathrm{H}$-bond interactions between protonated amines and $\mathrm{PO}_{\mathrm{x}}^{-}$terminating groups [109].

Two different types of non-bonded forces are established in host-guest SDAzeolite systems: Van der Waals and electrostatic interactions. The former are short-ranged, and hence very sensitive to the distance between the interacting atoms. Van der Waals interactions relate to the size and shape of the organic species and that of the zeolite structure which crystallizes around, and as a consequence are mainly responsible for the structure-directing effect in terms of the geometric relationship between hosts (their porous system) and guests (SDAs). In this way, van der Waals interactions determine how good the fit between the organic SDAs and the zeolite framework that crystallizes around is. For this reason, calculation of this type of interactions between SDAs and particular zeolite frameworks by molecular modeling techniques has been very useful to predict the ability of the 
organic species to direct the formation of particular zeolite frameworks: The higher these interactions, the better the host-guest adjustment, and hence the higher the ability of such particular host-guest system to be produced [110]. Originally these modeling techniques allowed for rational explanations of experimentally-observed structure-directing trends of organic species, but nowadays these can also be used to a priori predict the best SDA cation to direct the crystallization of a particular framework type [111,112]: This will be dealt in depth in Chapter 6 of this Volume. In addition, packing interactions, i.e. interactions between the organic cations when occluded in the confined environments of zeolite frameworks, are also relevant for the structure-directing phenomenon, and determine how the SDA cations pack within zeolite void volumes as a function of their size/shape and electrostatics, driven by steric and repulsive electrostatic interactions. Such packing interactions are particularly important in channel-based zeolite systems where the SDA cations locate close to each other without zeolite walls separating them (as occurs instead in cage-based systems).

Electrostatic interactions are mainly due to the interactions established between the positive charge of the cationic organic SDA species and the negative charge of the zeolite frameworks, which can be connectivity defects ( $\mathrm{Si}_{-} \mathrm{O}^{-}$ groups), inorganic anions like fluoride incorporated in the frameworks, or lowvalent dopants substituting for $\mathrm{Si}^{4+}$ (typically $\mathrm{Al}^{3+}$ or $\mathrm{B}^{3+}$ replacing $\mathrm{Si}^{4+}$ or divalent $\mathrm{M}^{2+}$ replacing $\mathrm{Al}^{3+}$ in AlPO networks). In order to maximize these interactions, it is reasonable to expect that the negative charge associated to the inorganic network will locate as close as possible to the positive charge of the SDA cations. Indeed, recent studies have shown that connectivity defects $\left(\mathrm{SiO}^{-}\right)$tend to locate close to the molecular charge center, unless steric shielding avoids it $[113,114]$. Such minimization of the $\mathrm{SDA}^{+} \ldots$ (zeolite) ${ }^{-}$distance between charged entities to maximize the electrostatic interactions has been used by us and others in order to direct the spatial incorporation of $\mathrm{Al}$ in zeolite networks in particular framework positions by rationally modifying the SDAs used in the synthesis [115-117], or to promote the development of chiral spatial distributions of dopants within achiral zeolite networks [118]. In another work, Lemishko and coworkers have found a competition between the electrostatic interactions between fluoride and $\mathrm{P}$ containing SDA cationic species, which are characterized by a high concentration of positive charge on the phosphorus atoms, and short-ranged van der Waals SDA $\cdots$ zeolite interactions as a function of the molecular structure [119]. The predominance of one or the other type of interaction will determine the mode of action of the structure-directing phenomenon; this is particularly important in phosphonium-based SDAs due to the higher concentration of positive charge on $\mathrm{P}$ compared to their $\mathrm{N}$ counterparts.

$\mathrm{H}$-bond interactions can also take place if the organic SDA species have $\mathrm{H}$ bond donor groups, as is the case for amine-based SDAs (rather than quaternary ammonium compounds). In our group we have shown that these H-bond interactions determine the supramolecular aggregation of chiral amines [83,120]. H-bond interactions have been shown to be pivotal for a transfer of chirality from organic chiral species into zeolite frameworks to occur [121], as will be dealt in Chapter 7 of this Volume. Even without amines or alcohol groups, strong $\mathrm{C}-\mathrm{H} \cdots \mathrm{O}-\mathrm{Si} \mathrm{H}$ - 
bonds may be stablished and have a role in the structure-direction of zeolites, as shown by Behrens et al in the case of nonasil synthesized using cobaltocenium and fluoride, where the cation resides fixed in a cage and rotational disorder only occurs at temperatures above the synthesis temperature [122].

Very recently a new type of host-guest interaction has been identified in the synthesis of silicoaluminophosphate molecular sieves by using quaternary ammonium compounds with hydroxyethyl branches [123,124]. In these SDAs, the terminal hydroxyl moieties display a strong tendency to form complexes with $\mathrm{Al}$ through coordination bonds in octahedral geometry, which leads to the formation of Al-O-Al linkages that are retained in the final zeolitic framework and even after calcination. The calcined materials may thus be interpreted as extensively violating the Loewestein rule (Al-O-Al avoidance in tetrahedral frameworks), although in the as-made materials both paired $\mathrm{Al}$ have, in fact, octahedral coordination. The discovery, anyway, leads to a new family of microporous materials with potentially new structural units and frameworks. The authors found that there seems to be an optimal degree of hydrophilicity of the SDA involved to promote the formation of these framework-bound SDA-containing molecular sieves.

Another kind of intermolecular interactions that have been exploited during the structure-directing phenomenon is hydrophobic $\pi-\pi$ type interactions between aromatic SDA cations. Such particular interactions have been used to promote the formation of large supramolecular aggregates through $\pi-\pi$ stacking of the aromatic rings, leading to large structure-directing entities that will drive the crystallization of zeolite frameworks with large pore-volumes [125-127]. This will be analyzed in Chapter 5 of this Volume, and hence no further details will be given here.

Hydrophobic interactions are also responsible for the crystallization of extralarge pore zeolites using small and flexible diammonium cations such as hexamethonium, which gives a number of different zeolite structures depending on the synthesis conditions (see Figure 6 above). These structures have very different porous systems, and hence these SDA dications have to pack in a different fashion within each pore system. These relatively small cations can direct the formation of extra-large pore zeolites like ITQ-33 (ITT) [128]; however, they do not form large micellar arrangements as surfactants do, neither behave like rigid and very large SDA species that direct large pore zeolite frameworks (like those in Figure 6-top). Therefore, hydrophobic interactions between the aliphatic spacer links of different hexamethonium cations have to be established to efficiently pack these molecules in extra-large pore zeolites and fill up the large void-volume in a cooperative fashion [30].

\section{Imidazolium-based cations as structure-directing agents}

So far in this chapter we have dealt with the properties that organic SDA species have to fulfill in order to efficiently direct the crystallization of zeolite materials, as well as the variables that can alter their mode of action and the host-guest chemistry involved in this phenomenon. Subsequent chapters of this Volume will 
be devoted to the different types of SDA species and trends in structure-direction, as well as to different tools that are available to understand the structure-directing phenomenon. This last section of the introductory chapter will analyze the use of imidazolium-based cations as SDAs in the synthesis of silica-based zeolite materials. This is, on one hand, because imidazolium cations are attracting an increasing interest in recent years and, on the other hand, because they may well exemplify several of the concepts outlined above.

An imidazolium is an aromatic cation derived from the imidazole ring by substitution reactions in which the $\mathrm{N}$ atoms act as the nucleophile. They are not 'quaternary' cations, since all the five atoms that build the charged ring have $\mathrm{sp}^{2}$ hybridization and, thus, cannot have four substituents. The ring itself is considerably rigid, small and planar, while substituents in the ring increase the size and may also increase the flexibility. They are scientifically and technologically relevant because imidazolium salts may behave as ionic liquids [129] and because they can be used to prepare persistent carbenes (Arduengo carbenes) [130]. It is worth noting that aqueous solutions of imidazolium compounds should not be confused with ionic liquids. Several examples of imidazolium cations relevant to this review are represented in Figure 9, together with their names and acronyms.

The first zeolite synthesis using imidazolium cations was reported by Zones in 1989 [131]. He obtained four already known high silica zeolites in hydroxide media (ZSM-12, ZSM-22, ZSM-23 and ZSM-48) using 123TMI, 13DMI and 13DiPI and $13 \mathrm{MiPI}$. However, in recent years several new zeolites have been discovered by combining the structure-directing effect of imidazolium cations (including those used by Zones) with other synthetic strategies for the discovery of new zeolites.

Table 1. New zeolites originally discovered through the use of imidazolium-based $\mathrm{SDAs}^{1}$

\begin{tabular}{llllll}
\hline Zeolite & ZFT $^{2}$ & Cation $^{3}$ & $\begin{array}{l}\text { Framework } \\
\text { Composition }\end{array}$ & Route $^{4}$ & Ref \\
\hline ITQ-12 & ITW & 134TMI & $\mathrm{SiO}_{2}$ & Highly concentrated $\mathrm{F}^{-}$ & 132 \\
SIZ-7 & SIV & 1E3MI & $\mathrm{CoAPO}$ & Ionothermal & 133 \\
IM-16 & UOS & 1E3MI & $(\mathrm{Ge}, \mathrm{Si}) \mathrm{O}_{2}$ & $\mathrm{Ge}^{-} \mathrm{F}^{-}$ & 134 \\
IM-20 & UWY & 1Bz3MI & $(\mathrm{Ge}, \mathrm{Si}) \mathrm{O}_{2}$ & ${\mathrm{Ge}, \mathrm{F}^{-}}^{-}$ & 135 \\
CIT-7 & CSV & 4b2345TMI & $\mathrm{SiO}_{2}(+\mathrm{Al}, \mathrm{Ti})$ & $\mathrm{Highly}^{\mathrm{H}}$ concentrated $\mathrm{F}^{-}\left(\mathrm{OH}^{-}\right)^{5}$ & 136 \\
CIT-13 & - & $\begin{array}{l}\text { oMBz23DMI, } \\
\text { mMBz23DMI }\end{array}$ & & $\mathrm{Ge}^{-}$ & 137 \\
& & & & \\
\hline
\end{tabular}

'True' zeolitic frameworks (i.e. three-dimensional fully connected tetrahedral (4.2) networks) but not interrupted frameworks are considered here, irrespective of their chemical composition. ${ }^{2}$ Zeolite Framework Type. ${ }^{3}$ Imidazolium used in the first report, acronyms according to Figure $9 .{ }^{4}$ Synthetic strategy (see text). ${ }^{5}$ Synthesis by the $\mathrm{OH}^{-}$route was also possible, in a much more limited range of conditions 


\title{
5.1 New zeolites discovered using imidazolium cations
}

\author{
5.1.1 ITW and CSV: Imidazolium and fluoride
}

The first zeolite discovered making use of imidazolium cations was ITQ-12 (ITW) [132], which was obtained with 134TMI (and also its isomer 123TMI) in concentrated conditions by the fluoride route. This zeolite is a small pore material that contains two types of cages: The D4R, in which fluoride resides, and a larger, obloid, relatively thin and slit-shaped $\left[4^{4} 5^{4} 6^{4} 8^{4}\right]$ cage in where the organic cation is occluded. This pure $\mathrm{SiO}_{2}$ material showed a large potential for the separation of propene and propane from its mixtures [138] and was the subject of quite extensive investigation from both the experimental and theoretical perspectives. One interesting result found by density functional theory calculations was that in the asmade material the Si-O bond was significantly more polarized than in the calcined zeolite [95]. This fact provided an important insight into the proposed structure direction role of fluoride towards D4R silica structures: The increased ionicity of the $\mathrm{Si}-\mathrm{O}$ bond decreases its directionality, thus relaxing the otherwise strained structure. Additionally, the combination of the fluoride and imidazolium effects was strong enough to reverse the order of stability of two $\mathrm{SiO}_{2}$ zeolites, as proven by the in situ transformation of the initially crystallized $134 \mathrm{TMIF}-\mathrm{SiO}_{2}-\mathrm{TON}$ into 134TMIF-SiO ${ }_{2}$-ITW, despite the fact that TON is denser, less strained and, hence, thermodynamically more stable than ITW in the absence of guests [96].

A total of five different imidazolium cations [139,140,143], in combination with fluoride, were eventually found to direct to ITW with different degrees of specificity in structure-direction, following the decreasing order 123TMI > 1E23DMI > 13DMI 134TMI > 2E134TMI (see Figure 9 for the acronyms and Figure 10 for the specificity order). For the general conditions used, this order can be derived from the range of chemical compositions (particularly $\mathrm{H}_{2} \mathrm{O} / \mathrm{SiO}_{2}$ ratios) and crystallization time needed to obtain the material, and from the possible prior crystallization of a different zeolite. 123TMI was effective at any of the $\mathrm{H}_{2} \mathrm{O} / \mathrm{SiO}_{2}$ ratios tried, which included rather dilute conditions $\left(\mathrm{H}_{2} \mathrm{O} / \mathrm{SiO}_{2}\right.$ up to 24.5) with no sign of competing phases. For 1E23DMI, direct crystallization of ITW occurred only at relatively high concentrations $\left(\mathrm{H}_{2} \mathrm{O} / \mathrm{SiO}_{2} \leq 13\right)$, while at more diluted conditions MTW competed. It was, however, shown that $1 \mathrm{E} 23 \mathrm{DMI}-\mathrm{F}-\mathrm{SiO}_{2}-\mathrm{MTW}$ could be transformed in situ to ITW at high concentrations (while the opposite, i.e. the transformation of 1E23DMI-F-ITW into MTW at high dilution didn't occur), in an additional example of "dense and stable" to "open and strained" zeolite transformation driven by host-guest interactions [140]. On the other hand, 13DMI and 134TMI needed increasing concentrations to crystallize ITW, with TON competing (but finally transforming to ITW, as stated above) [96]. The less specific SDA for ITW was 2E134TMI, a cation significantly larger in size that only worked at higher temperatures $\left(175\right.$ or 185 instead of $150^{\circ} \mathrm{C}$ for the rest of the examples) and that produced HPM-1 (the pure silica version of the chiral STW zeolite, see below) [141] at rather high concentrations and HPM-2 (a layered precursor to zeolite MTF) [142] at intermediate dilutions. Interestingly, both phases were unstable under the crystallization conditions and eventually transformed to ITW 
under much prolonged heating (well over 30 days). The possibility that a small degradation product acted as the true SDA, rather than the rather large 2E134TMI, had to be considered because of the prolonged heating at high temperature and the 'degraded SDA' examples given above. However, ${ }^{13} \mathrm{C}$ MAS NMR of the zeolite demonstrated 2E134TMI was occluded intact into the zeolite [143]. The STW to ITW zeolite transformation is not as remarkable as the TON to ITW or MTW to ITW transformations commented above, since it probably doesn't revert the thermodynamic stability difference of the $\mathrm{SiO}_{2}$ frameworks involved: STW is less dense (framework density 15.2 compared to $18.1 \mathrm{Si} / 1000 \AA^{3}$ ) and likely more strained (higher concentration of D4R units) than ITW.

Table 2 collects the percentage transfer of iodide salts from water to chloroform solutions, proposed as a qualitative measure of the hydrophobicity of the cations [51], for several imidazolium and quaternary ammonium cations. The different behaviour between both types of cations is clearly evident. The five small imidazolium cations that are able to produce ITW appear to be significantly more hydrophobic than quaternary ammonium cations within a similar range of $\mathrm{C}$ and $\mathrm{N}$ atoms per charge. Interestingly, also, the molecular shape apparently contributes largely to the observed hydrophobicity, since the three isomers with formula $\mathrm{C}_{6} \mathrm{~N}_{2} \mathrm{H}_{11}$ (1E3MI, 123TMI and 134TMI) display significantly different percentage transfers. On the other hand, the most specific structure-direction effects among this imidazolium series are provided by cations with an intermediate hydrophobicity, which is, however, significantly lower than that proposed by Kubota and coworkers for quaternary ammonium SDAs that work well. The less hydrophobic cation (1E3MI) is a rather unselective SDA producing zeolites not highly demanding of strong structure direction (mainly TON and, in more restricted conditions, MFI) [69]. However, the next most hydrophobic cations (123TMI and 1E23DMI) are the most specific SDAs. It has in fact been argued that a relatively high hydrophilic character may improve the ionization-based flexibility enhancement observed in these fluoride-containing silica materials $[139,140]$. 1E3MI may be either too hydrophilic or too flexible [140], when compared to the rest of these imidazolium cations. Finally, it is worth mentioning that, during all these studies, the Villaescusa rule was strictly observed.

Table 2. Literature data for the transfer of imidazolium [144,140] and quaternary ammonium [51] SDA iodide salts from water to chloroform solution. ${ }^{1}$

\begin{tabular}{lll}
\hline Salt & $(\mathbf{C}+\mathbf{N}) / \mathbf{q}$ & \% Transfer \\
\hline $13 \mathrm{DMI}^{+} \mathrm{I}^{-}$ & 7 & 22.5 \\
$134 \mathrm{TMI}^{+} \mathrm{I}^{-}$ & 8 & 28.8 \\
$123 \mathrm{TMI}^{+} \mathrm{I}^{-}$ & 8 & 16.5 \\
$1 \mathrm{E} 3 \mathrm{MI}^{+} \mathrm{I}^{-}$ & 8 & 8.1 \\
$1 \mathrm{E} 23 \mathrm{MMI}^{+} \mathrm{I}^{-}$ & 9 & 17.7 \\
$2 \mathrm{E} 134 \mathrm{TMI}^{+} \mathrm{I}^{-}$ & 10 & 21.6 \\
$\mathrm{TMA}^{+} \mathrm{I}^{-}$ & 5 & 0 \\
$\mathrm{TEA}^{+} \mathrm{I}^{-}$ & 9 & 0 \\
$\mathrm{TPA}^{+} \mathrm{I}^{-}$ & 13 & 30 \\
$\mathrm{TBA}^{+} \mathrm{I}^{-}$ & 17 & 90 \\
\hline
\end{tabular}


${ }^{1}$ Acronyms for the imidazolium cations are given in Figure 9. The quaternary ammonium cations are tetramethyl- $\left(\mathrm{TMA}^{+}\right)$, tetraethyl- $\left(\mathrm{TEA}^{+}\right)$, tetrapropyl- $\left(\mathrm{TPA}^{+}\right)$and tetrabutylammonium $\left(\mathrm{TBA}^{+}\right)$.

A more recent example of a new zeolite topology discovered through the use of imidazolium cations is CIT-7 (CSV) [136]. The most specific SDA used is a dication with a tetramethylene linker (4b2345TMI) although the trimethylene and pentamethylene variants and a particular monocation (2E13DMI) also worked with a lesser strength. Importantly, most of the synthesis described used the fluoride route in concentrated conditions but the hydroxide route appears also to work in this case, although in a much more limited extent (only one unseeded synthesis was reported). The structure of CIT-7 comprises a two-dimensional system of interconnected 10 and $8 \mathrm{MR}$ pores with a relatively large $\left[4^{8} 5^{4} 6^{8} 8^{2} 10^{2}\right]$ cavity at the crossing. Very interestingly is, in our opinion, the presence in CIT-7 of a small $\left[4^{4} 5^{2}\right]$ cage which resembles the $\left[4^{6}\right]$ or D4R cage and that can, in fact, be formally considered as derived from that cage by insertion of an additional $\mathrm{Si}$ atom in between two corners of the D4R unit. With regard to structure-direction in CIT-7 it may be highly relevant to find out if fluoride is occluded in the $\left[4^{4} 5^{2}\right]$ cage and the precise location and conformation of the organic SDA, so further studies are well merited.

\subsubsection{SIV: Ionothermal synthesis}

The so-called ionothermal synthesis of zeolite-like analogues was developed by Morris's group at St. Andrews and consists in the use of ionic liquids or deep eutectic mixtures as solvents and as 'templates' or structure-directing agents $[145,146,147]$. In the case of eutectic mixtures they don't really act as templates but as template-delivery agents by the in situ degradation of the urea derivative of the mixture, as commented above [72]. In the case of ionic liquids, which are frequently salts of imidazolium or pyridinium derivatives, the cation in the salt acts as SDA, most frequently as itself but occasionally also after degradation and rearrangement [70].

While it may have additional advantages (like a very small vapour pressure that doesn't build up a high autogenous pressure) the idea behind the ionothermal synthesis is that it should avoid the competition between solvent and SDA for interacting with the inorganic components of the mixture. In fact, this may profoundly transform the mechanism of structure-direction, since no 'hydrophobic hydration sphere' can be involved in this case. Ionic liquids are frequently highly hygroscopic and, hence, are never fully dry and water (and fluoride) may also be added as mineralizers or be introduced together with the reagents, so one could wonder if the frontiers between the ionothermal synthesis and the hydrothermal synthesis with fluoride in concentrated conditions may blurry for extremely low $\mathrm{H}_{2} \mathrm{O} / \mathrm{SiO}_{2}$ ratios. There are however important differences that distinguish both routes. First, in the ionothermal synthesis the ionic liquids are, of course, in 'solvent' amounts (i.e., many times the molar amount of tetrahedral atoms), while in the hydrothermal synthesis they usually do not exceed a $\mathrm{SDA} / \mathrm{SiO}_{2}$ ratio of 0.5 or 
0.6. Second, even in wet ionic liquids water seems to be 'deactivated', meaning it displays a reduced chemical reactivity. Apparently, this is so as far as water remains molecularly dispersed or in small clusters and with strong anion-water interactions that reduce the nucleophilicity of water [146]. Also at variance with the hydrothermal imidazolium fluoride synthesis that works very well for fully connected silica zeolites, the ionothermal route works better for phosphate based materials that, most typically, have hanging P-O bonds, i.e. frequently they are not fully connected but either interrupted frameworks or layered materials, possible due to a slow rate of hydrolysis caused by the decreased water reactivity commented above.

The ionothermal route has been successful in crystallizing many new phosphate-based materials, including one fully connected material with a new zeolite topology: SIZ-7 (SIV) [133]. This is a cobalt aluminophosphate with a threedimensional system of small pores built from double crankshaft chains and was prepared with $1 \mathrm{E} 3 \mathrm{MI}^{+}$bromide as solvent. We have considered above that $1 \mathrm{E} 3 \mathrm{MI}$ is a poor SDA in hydrothermal syntheses and, while it can act differently in an ionothermal synthesis it still doesn't seem to be a very specific SDA. For instance, with a CoAlPO composition it only produced physical mixtures of SIZ-7 (SIV), SIZ-8 (framework type AEI) and SIZ-9 (SOD), while in pure $\mathrm{AlPO}_{4}$ compositions it yielded SIZ-1 (an interrupted framework), SIZ-3(AEL), SIZ-4 (CHA) or SIZ-5 (AFO) depending on the presence and amount of water and fluoride.

It is interesting that the ionothermal synthesis doesn't work well for silicabased materials. So far, only SIZ-12, a fully connected but non-porous $\mathrm{SiO}_{2}$ phase with a framework density similar to cristobalite, has been prepared as isolated crystals among a lot of amorphous solid [146,147]. The synthesis conditions have so far not been revealed but, since the material is dense and doesn't occlude any organics, structure-direction in this case didn't proceed through the typical organic-inorganic host-guest interactions.

\subsubsection{UOS, UWY and CIT-13: Imidazolium, fluoride and germanium}

By combining the structure-directing effects of imidazolium cations, fluoride anions and germanium, three new zeolite structures were discovered: IM-16 (UOS) using 1E3MI [134], IM-20 (UWY) with 1B3MI [135] and CIT-13 using mMBz23DMI (and also oMBz23DMI in a more restricted compositional window [137]). As expected, because of the F and Ge roles, the three of them contain D4R units and this is likely the main effect affording their discovery. In fact, as we have commented before, 1E3MI shows no specificity at all in the absence of Ge. Because of its similarity with 1E3MI, the slightly longer and more flexible 1B3MI is also unlikely to exert a strong structure-direction of its own. Finally, CIT-13 is described in terms of dense cfi layers (first found in CFI [148], a one-dimensional 14MR material) connected through the D4R units, resulting in the first zeolite containing a bidimensional system of extra-large 14MR and medium 10MR pores. The relatively large benzylimidazolium derivatives that afford CIT-13 (who were later expanded to the slightly smaller mMBz3MI and oMBz3MI) [149] would help stabilize the relatively large volume by host-guest interactions, while most Ge 
was found in the D4R units. Thus, in all these three cases the main actor that directs the crystallization is likely Ge (and fluoride).

\subsection{New compositions attained with imidazolium cations}

In addition to the discovery of new zeolite structures, imidazolium cations have afforded the preparation of new zeolite compositions. Among these, the synthesis in pure form of the chiral zeolite HPM-1 (STW) is highly relevant [141] because of its implication in possible applications. This zeolite contains a helicoidal medium pore that could be useful in asymmetric catalysis and adsorption applications (see below). The STW structure type was first discovered in SU-32 [150], a germanosilicate prepared with diisopropylamine and with the help of the structure directing effects of Ge and fluoride (STW contains a large concentration of D4R). All these combined effects were not strong enough to produce pure SU-32 but mixtures with $\mathrm{SU}-15, \mathrm{GeO}_{2}$ and/or amorphous solids. Unfortunately, SU-32 suffers from the stability problems typically inherent to germanosilicates with a large Ge content, which tend not only to collapse upon calcination but also by hydrolysis with ambient moisture at room temperature. By contrast pure silica HPM-1 has the outstanding thermal and hydrothermal stability typical of $\mathrm{SiO}_{2}$ polymorphs with no connectivity defects.

The synthesis of HPM-1 in silica form made use of 2E134TMI with fluoride in highly concentrated conditions and produced the zeolite free of any impurities, despite prior theoretical predictions that such a silica polymorph could not be synthesized. The predictions were based in the lack of a 'flexibility window' for STW [151] or in the too strained structure for silica [152] but both considered as relevant material the 'clean', calcined $\mathrm{SiO}_{2}$ structure. A broad flexibility window (the ability of the structure to deform without too large an energetic cost) [153] is considered necessary for a structure to be feasible, which has been rationalized as a way to improve the likelihood of a good host-guest match [154]. However, from the point of view of being able to crystallize a material, the important structure is not the clean calcined material but, obviously, the as-made one. As stated above, host-guest interactions, particularly with fluoride and imidazolium cations, may increase the ionicity of the framework [95,96], and this has been shown to be the case also for HPM-1: The structural solution of the as-made material showed a large deformation of the $\left[\mathrm{SiO}_{4 / 2}\right]$ tetrahedra [155], indeed supporting an enhanced flexibility. Fluoride was found in the D4R cages and the imidazolium cations in the larger $\left[4^{6} 5^{8} 8^{2} 10^{2}\right]$ cavity in a 'locked' conformation, in a further example of a strong structure direction by the combined effects of fluoride and imidazolium cations. This synthetic route also afforded the incorporation of Al into HPM-1, and the material was found to be an outstanding catalyst for the skeletal isomerization of normal butene [156].

Later on, Schmidt and coworkers also synthesized pure silica HPM-1 using $12345 \mathrm{PMI}$ by the concentrated fluoride route [112] following a study based on a computational method for determining chemically feasible SDAs for specific structures [157]. The method considers not only the host-guest interaction energy but also the possibility of synthesizing the SDA by known chemical transfor- 
mations of a library of commercially available organic precursors. When the same cation was used for the synthesis of aluminosilicate zeolites, however, the aluminosilicate version of zeolite RTH was obtained instead [158]. The same aluminosilicate zeolite was obtained with a range of different imidazolium cations $[159,160]$. A layered precursor of RTH, termed CIT-10, was also synthesized using an imidazolium-based dication with a pentamethylene linker, 5b2345TeMI [161].

\subsection{Achieving homochirality}

The discovery that a dication, 4b2345TeMI, was able to crystallize STW with the imidazolium moieties occupying two different cages, first reported as supplementary information to the synthesis of CIT-7 [136], suggested a way to control the crystallization of this chiral zeolite towards a scalemic conglomerate. This zeolite in principle crystallizes as a racemic conglomerate, i.e. as a mixture of equal amounts of homochiral crystals of both hands. By introducing a rigid cyclopropane moiety in the middle of the spacer and using enantiopure versions of the resulting chiral dications, $R$ - and $S$-cprdMbTeMI (Figure 9, bottom right corner), Brand and coworkers were able to produce very recently enantioenriched germanosilicate and aluminogermanosilicate [162] versions of this zeolite. Presumably, the linker's chirality imposed in some extent the spatial disposition of consecutive cages, directing the crystallization preferentially towards crystals of one hand. The ring opening of 1,2-epoxyalkanes in aluminium-containing enantioenriched STW showed significant enantiomeric excess, while adsorption of 2butanol in enantioenriched germanosilicates also proved a certain degree of enantioselectivity.

\section{Conclusions}

The use of organic structure-directing agents in the synthesis of zeolite materials has rendered a tremendous impact on the discovery of new zeolite topologies as well as new chemical compositions of the zeolite networks, which have greatly expanded the potential of application of the resulting zeolitic materials. To be efficient structure-directing agents, organic species have to fulfill a series of chemical conditions, in particular display a high hydrothermal stability, and particular size/shape, hydrophobic/hydrophilic and rigidity/flexibility properties, which have been analyzed in this introductory chapter, together with some applications directly derived from these particular properties. Nonetheless, the extensive investigation carried out during the last decades on the use of new organic species as structure-directing agents has enlarged the range of conditions where they efficiently direct the crystallization of zeolitic materials, rendering new fascinating materials through a rational selection of the organic species to be used. The following chap- 
ters of this Special Issue will be devoted to analyze in detail recent trends in the science of structure-direction by organic species.

\section{Acknowledgements}

Funding from the Spanish Ministry of Economy, Industry and Competitiveness (through projects MAT2015-65767-P and MAT2015-71117-R) is acknowledged. 
Figures

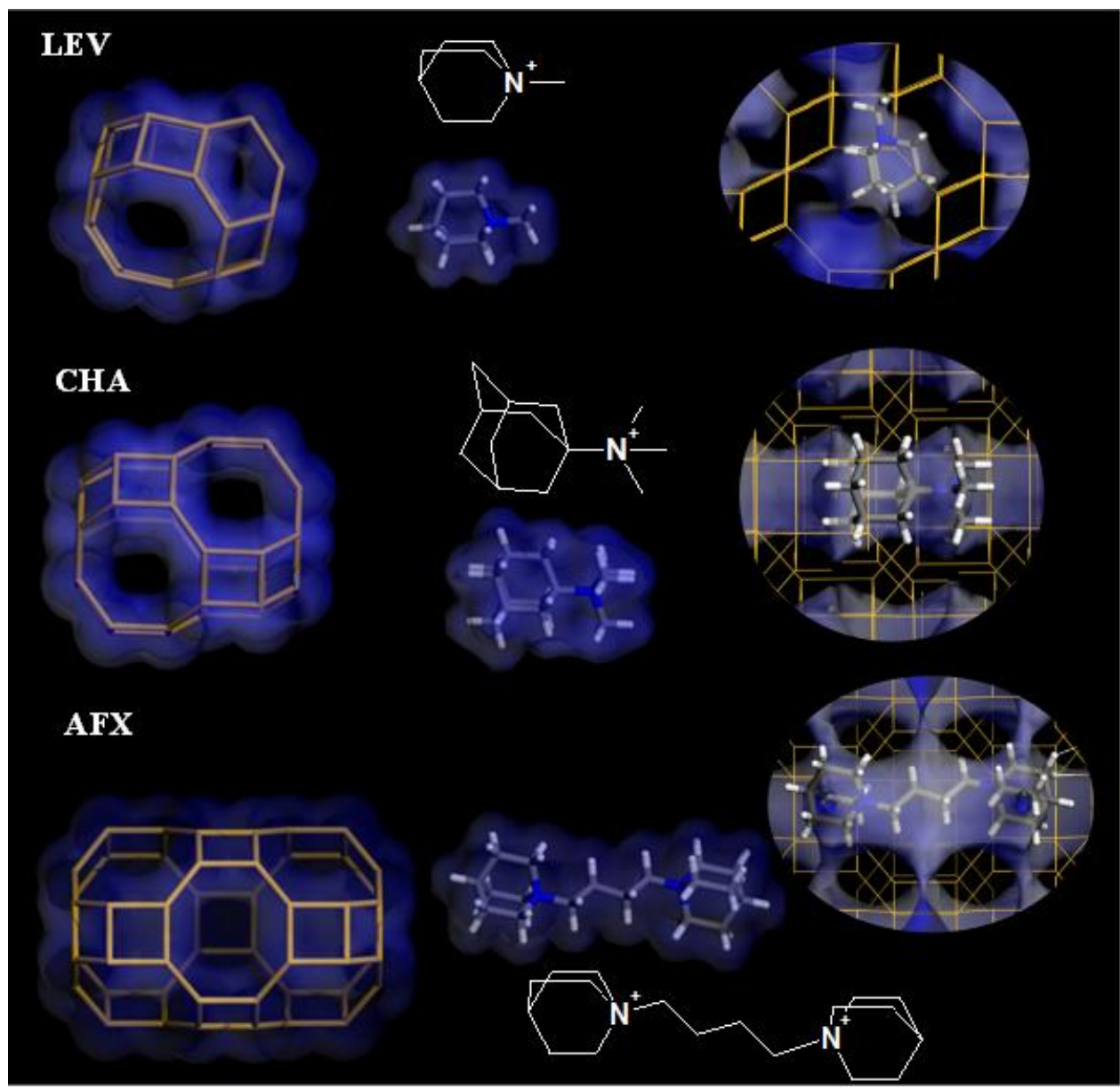

Figure 1. Cage-based zeolite frameworks with different cage sizes synthesized with related organic cations of increasing size. Adapted from [25]. 


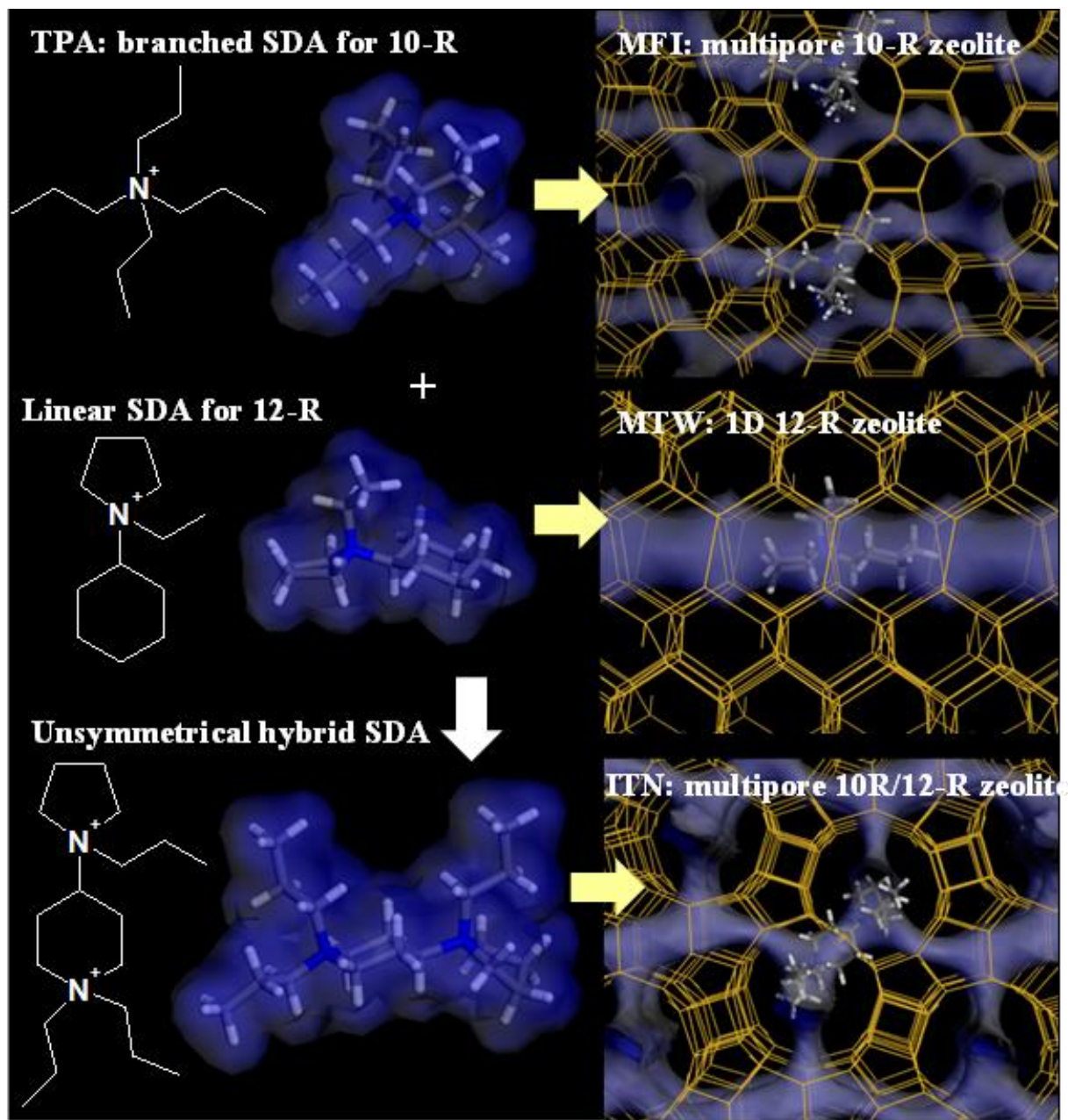

Figure 2. Rational design of SDAs for multipore zeolites based on 10-ring and 12ring multidimensional channel systems [35]. Reprinted (adapted) with permission from [31]; Copyright 2015 The Royal Society of Chemistry. 


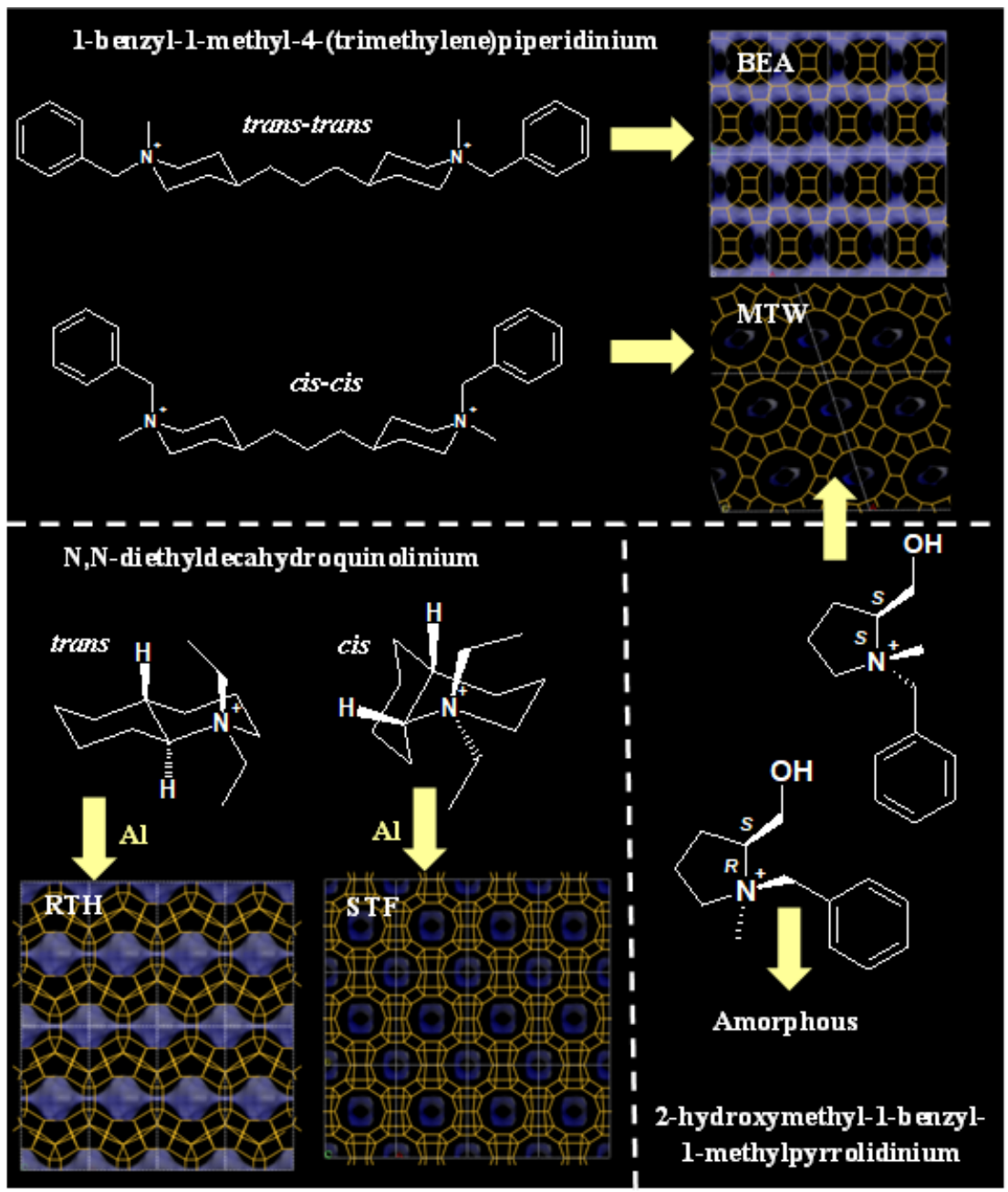

Figure 3. Diastereoselective structure-directing effects of 1-benzyl-1-methyl-4(trimethylene)piperidinium (top), N,N-diethyl-decahydroquinolinium (bottomleft) and 2-hydroxymethyl-1-benzyl-1-methylpyrrolidinium (bottom-right). Reprinted (adapted) with permission from [44], Copyright 1999 Elsevier Science B.V., and from [45], Copyright 2002 American Chemical Society 


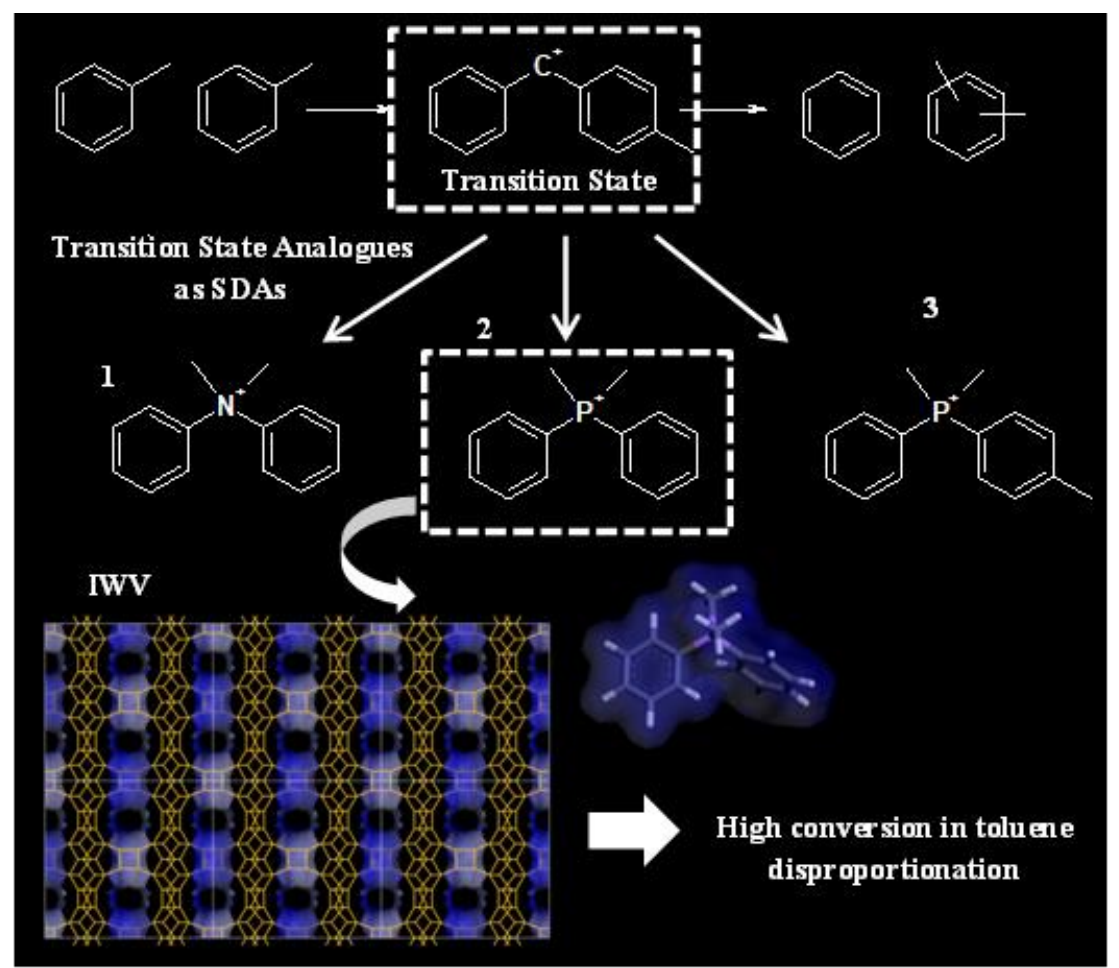

Figure 4. Top: mechanism of the toluene disproportionation to produce xylenes; middle: organic SDA cations selected as transition state analogues for this reaction; bottom: IWV framework produced by TSA 2 which showed a high conversion in toluene disproportionation. Reprinted (adapted) with permission from [47];

Copyright 2017 American Association for the Advancement of Science. 


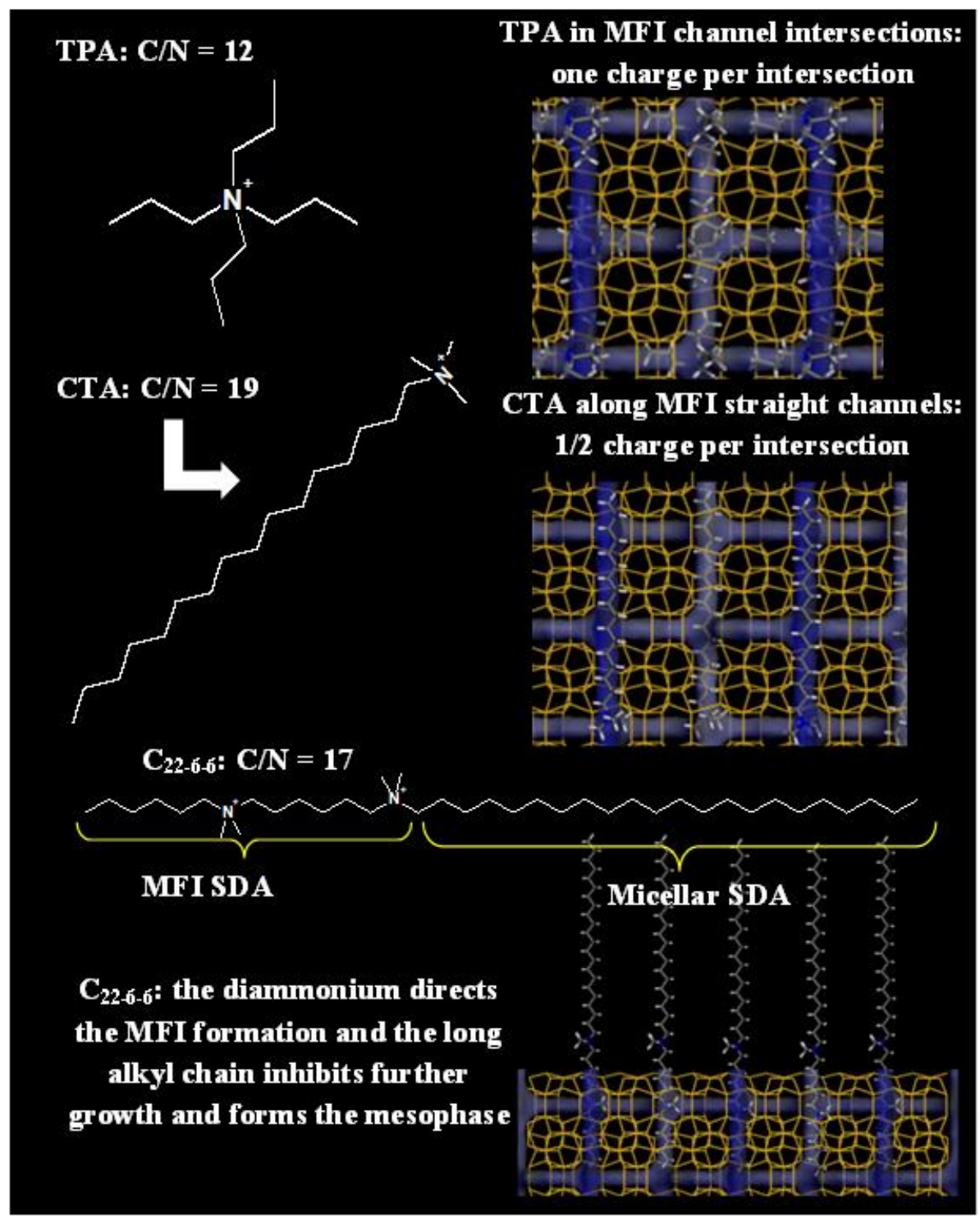

Figure 5. SDA cations with different hydrophobicity giving place to MFI zeolites with different properties $[57,58]$. 


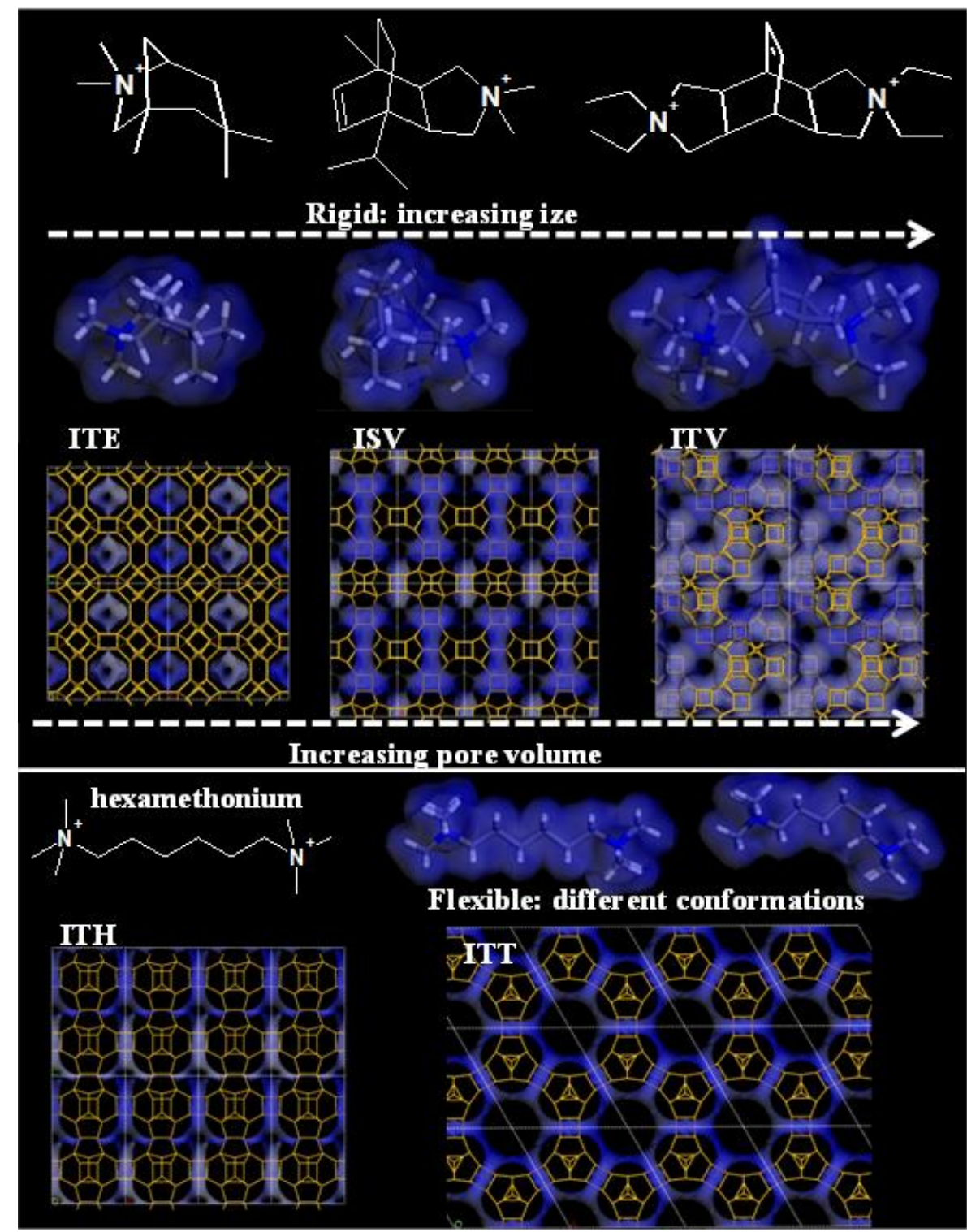

Figure 6. SDA cations with different rigidity/flexibility properties: top: rigid SDAs giving selectively frameworks of larger pore volume; bottom: flexible hexamethonium giving different frameworks as a function of $\mathrm{Si} / \mathrm{Ge}$ ratio. Reprinted (adapted) with permission from [19], Copyright 20132013 WILEY-VCH Verlag GmbH \& Co. KGaA, Weinheim. 


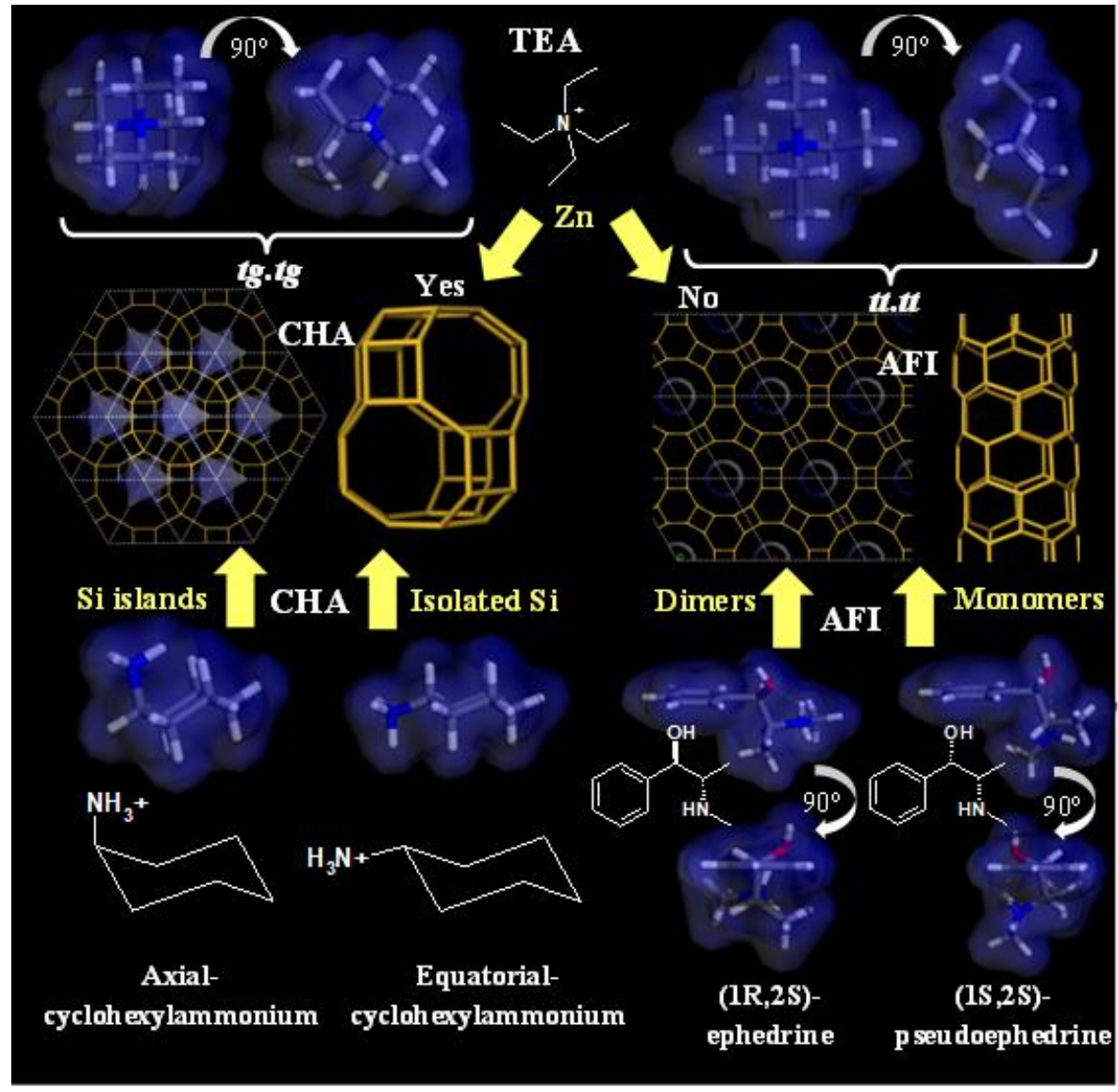

Figure 7. Effect of conformational space as a consequence of molecular flexibility on SDAs: $t g . t g / t$.tt conformers of TEA (top), axial- and equatorial conformers of cyclohexylammonium (bottom-left) and conformers of ephedrinium and pseudoephedrinium (bottom-right) [77,79,83]. 


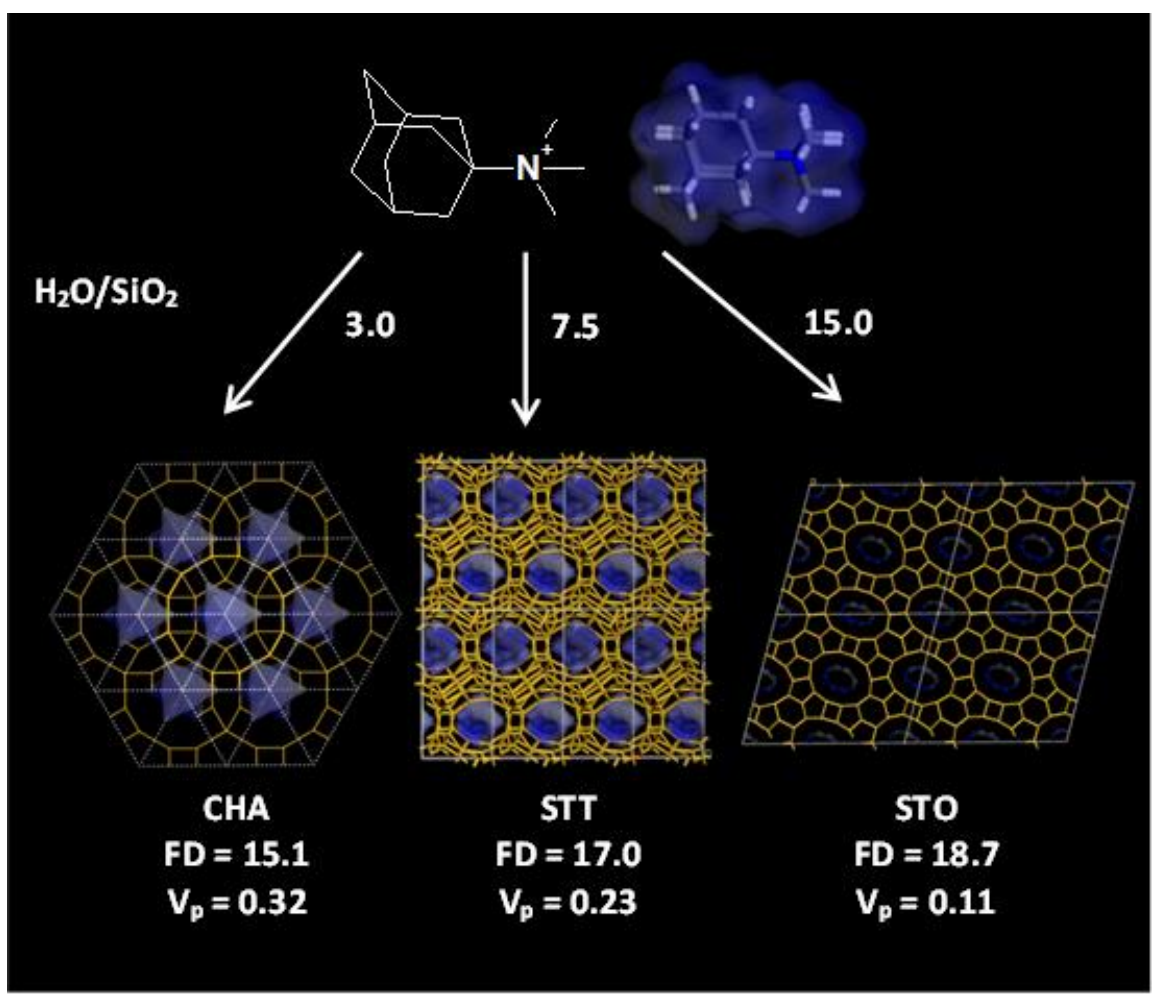

Figure 8. Effect of $\mathrm{H}_{2} \mathrm{O} / \mathrm{SiO}_{2}$ ratio on the structure-directing effect of trimethyladammantammonium in the synthesis of zeolites. Reprinted (adapted) with permission from [97], Copyright 1999 Kluwer Academic Publishers, and from [99], Copyright 2005 American Chemical Society. 

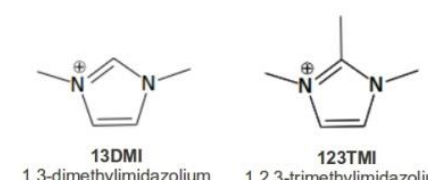

123TMI
1,2,3-trimethylimidazolium
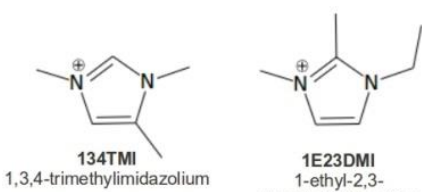

1-e23DMI
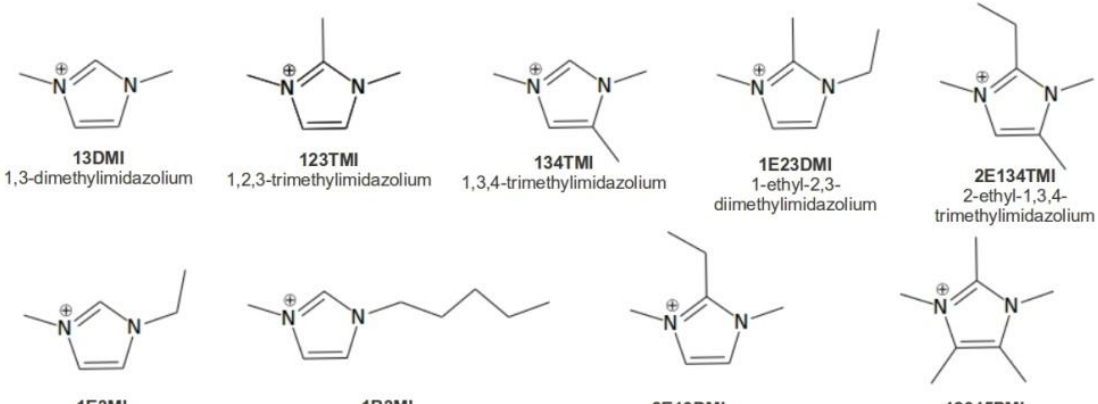

diimethylimidazol

2-ethyl-1,3,4-

1-ethyl-3-methylimidazolium

1B3MI
1-butyl-3-methylimidazolium
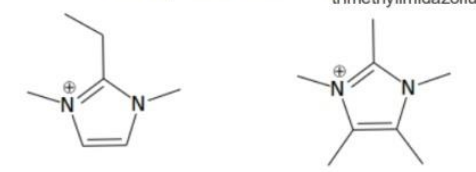

2E13DMI

$12345 \mathrm{PMI}$
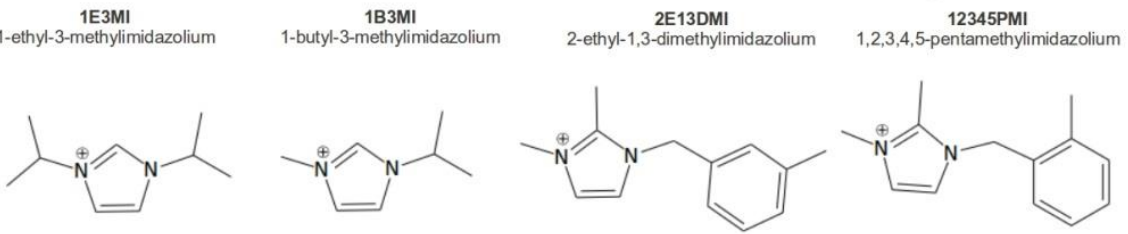

13DiPI

$\begin{array}{cc}\text { 13DiPI } & \text { 1iP3MI } \\ \text { 1,3-disopropylimidazolium } & \text { 1-isopropyl-3-methylimidazolium }\end{array}$
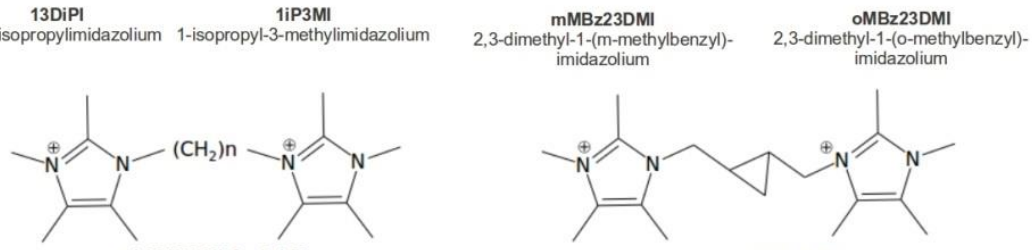

$n$ b2345TeM! $[n=3,4,5]$
'n'methylene-bis-(2,3,4,5-tetramethylimidazolium)
$[n=t r i$, tetra, penta] $]$
3,3 '-cyclopropane-1,2-diylbis(methylene)bis(2345tetramethylimidazolium)

$n$ b2345TeM! $[n=3,4,5]$
'n'methylene-bis-(2,3,4,5-tetramethylimidazolium)
$[n=t r i$, tetra, penta] $]$
3,3 '-cyclopropane-1,2-diylbis(methylene)bis(2345tetramethylimidazolium)

Figure 9. Several imidazolium cations relevant to this review, with their names and the acronyms used here. The five cations in the first row produced ITW. The cation at the top right also afforded the chiral pure silica STW. The first cation in the second row produced SIV by the ionothermal route and UOS by the fluoride, germanium route (the same route that afforded UWY with the second cation in the same row and CIT-13 with the benzyl derivatives in the third row). The dication with $\mathrm{n}=4$ in the last row afforded the discovery of CSV. The dication in the bottom right is chiral (not detailed in the figure) and has been used in enantiopure form to produce scalemic conglomerates of germanosilicates and aluminogermanosilicate STW [162]. 


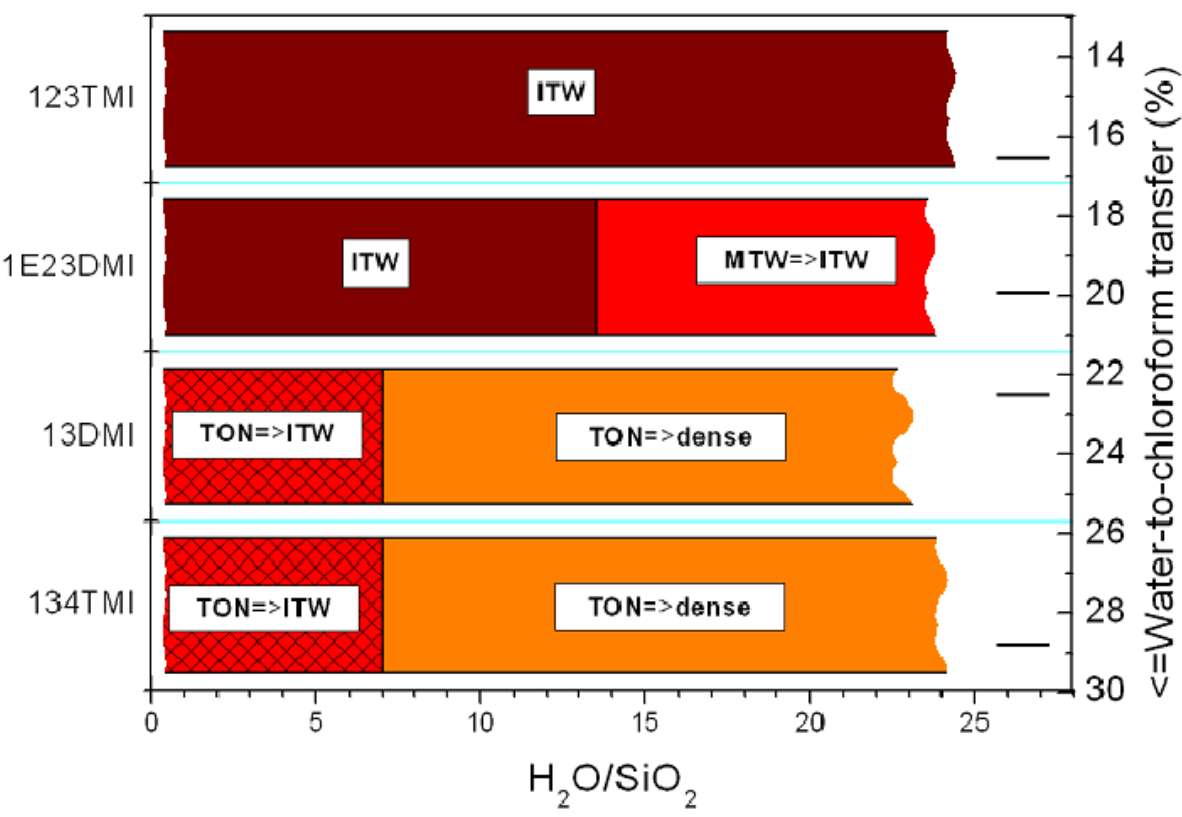

Figure 10. Approximate crystallization fields for pure silica zeolites in fluoride media at $150^{\circ} \mathrm{C}$ using four imidazolium based SDAs able to crystallize zeolite ITW at that temperature. The specificity in structure-direction towards ITW increases from bottom to top, i.e., as opposed to the $\%$ transfer from water to chloroform (shown at the right). Reprinted with permission from [140], Copyright 2013 American Chemical Society. 


\section{References}

1. Cejka J, Corma A, Zones SI (2010) Zeolites and catalysis: Synthesis reactions and applications. Wiley, Weinheim.

2. Davis ME (2002) Ordered porous materials for emerging applications. Nature 417: 813-821.

3. Barrer RM (1948) Synthesis of a zeolitic mineral with chabazite-like sorptive properties. J Chem Soc 127-132.

4. Rabo JA, Schoonover MW (2001) Early discoveries in zeolite chemistry and catalysis at Union Carbide, and follow-up in industrial catalysis, App Cat A 222: 261-275.

5. Breck DW, Eversole EG, Milton RM (1956) New synthetic crystalline zeolites. J Am Chem Soc 78: 2338-2339.

6. Sherman JD (1999) Synthetic zeolites and other microporous oxide molecular sieves. Proc Natl Acad Sci 96: 3471-3478.

7. Barrer RM, Denny PJ (1961) Hydrothermal chemistry of the silicates. Part IX.* Nitrogenous aluminosilicates. J Chem Soc 971-982.

8. Kerr GT, Kokotailo GT (1961) Sodium zeolite ZK-4, a new synthetic crystalline aluminosilicate, J Am Chem Soc 83:4675-4675.

9 Kerr GT (1966) Chemistry of crystalline aluminosilicates. II. The synthesis and properties of zeolite ZK-4. Inorg Chem 5:1537-1539.

10. Wadlinger RL, Kerr GT, Rosinski EJ (1967) US Patent 3,308,069.

11. Argauer RJ, Landolt GR (1972) US Patent 3,702,886.

12. Kokotailo GT, Chu P, Lawton SL et al (1978) Synthesis and structure of synthetic zeolite ZSM-11. Nature 275:119-120.

13. Kerr GT (1963) Zeolite ZK-5: A new molecular sieve. Science 140:1412.

14. Wilson ST, Lok BM, Flanigen EM (1982) US Patent 4,310,440.

15. Wilson ST, Lok BM, Messina CA et al (1982) Aluminophosphate molecular sieves: a new class of microporous crystalline inorganic solids. J Am Chem Soc 104:1146-1147.

16. Lok BM, Cannan TR, Messina CA (1983) The role of organic molecules in molecular sieve synthesis. Zeolites 3:282-291.

17. Kundy CS, Cox PA (2005) The hydrothermal synthesis of zeolites: Precursors, intermediates and reaction mechanism. Microporous Mesoporous Mater 82:1-78.

18. Gies H, Marler M (1992) The structure-controlling role of organic templates for the synthesis of porosils in the system $\mathrm{SiO}_{2} /$ template/ $\mathrm{H}_{2} \mathrm{O}$. Zeolites 12:42-49.

19. Moliner M, Rey F, Corma A (2013) Towards the rational design of efficient organic structure-directing agents for zeolite synthesis. Angew Chem Int Ed 52:13880-13889.

20. Burton AW, Zones SI (2007) Organic molecules in zeolite synthesis: Their preparation and structure-directing effects. Stud Surf Sci Catal 168:137-179.

21. Nakagawa Y (1994) US Patent 5,281,407.

22. Xie D, McCusker LB, Barlocher C et al (2013) SSZ-52, a zeolite with an 18-Layer aluminosilicate framework structure related to that of the DeNOx catalyst $\mathrm{Cu}-\mathrm{SSZ}-13$. J Am Chem Soc 135:10519-10524.

23. Elomari S (2003) US Patent 6,616,911.

24. Lew CM, Davis TM, Elomari S (2016) Synthesis of new molecular sieves using novel structure-directing agents, Chapter 2 in Verified Syntheses of Zeolitic Materials, 3rd Revised Edition, pp 29-35. 
25. Moliner M, Rey F, Corma A (2016) Synthesis design of new molecular sieves, Chapter 3 in Verified Syntheses of Zeolitic Materials, 3rd Revised Edition, pp 36-41.

26. Pérez-Pariente J, Gómez-Hortigüela L (2008) The role of templates in the synthesis of zeolites, Chapter 3 in Zeolites: from model materials to industrial catalysts, pp 33-62.

27. Davis ME, Lobo R (1992) Zeolite and molecular sieve synthesis. Chem Mater 4:756768.

28. Ikuno T, Chaikittisilp W, Liu Z et al (2015) Structure-directing behaviors of tetraethylammonium cations toward zeolite beta revealed by the evolution of aluminosilicate species formed during the crystallization process. J Am Chem Soc 137:14533-14544.

29. Zones SI, Burton AW, Lee GS et al (2007) A study of piperidinium structuredirecting agents in the synthesis of silica molecular sieves under fluoride-based conditions. J Am Chem Soc 129:9066-9079.

30. Jiang J, Yu J, Corma A (2010) Extra-large-pore zeolites: bridging the gap between micro and mesoporous structures. Angew Chem Int Ed 49:3120-3145.

31. Li J, Corma A, Yu J (2015) Synthesis of new zeolite structures. Chem Soc Rev 44:7112-7127.

32. Jiang J, Xu Y, Cheng P et al (2011) Investigation of extra-large pore zeolite synthesis by a high-throughput approach. Chem Mater 23:4709-4715.

33. Li Y, Yu J (2014) New stories of zeolite structures: their descriptions, determinations, predictions, and evaluations. Chem Rev 114:7268-7316.

34. Moliner M, González J, Portilla MT et al (2011) A new aluminosilicate molecular sieve with a system of pores between those of ZSM-5 and Beta zeolite. J Am Chem Soc 133:9497-9505.

35. Willhammar T, Sun J, Wan W et al (2012) Structure and catalytic properties of the most complex intergrown zeolite ITQ-39 determined by electron crystallography. Nat Chem 4:188-194.

36. Moliner M, Willhammar T, Wan W et al (2012) Synthesis design and structure of a multipore zeolite with interconnected 12- and 10-MR channels. J Am Chem Soc 134:6473-6478.

37. Moliner M, Martínez C, Corma A (2015) Multipore zeolites: synthesis and catalytic applications. Angew Chem Int Ed 54:3560-3579.

38. Wang Z, Yu J, Xu R (2012) Needs and trends in rational synthesis of zeolitic materials. Chem Soc Rev 41:1729-1741.

39. Burton AW, Zones SI, Elomari S (2005) The chemistry of phase selectivity in the synthesis of high-silica zeolites. Curr Opin Colloid Interface Sci 10:211-219.

40. Boal BW, Zones SI, Davis ME (2015) Triptycene structure-directing agents in aluminophosphate synthesis. Microporous Mesoporous Mater 208:203-211.

41. Jackowski A, Zones SI, Hwang SJ et al (2009) Diquaternary ammonium compounds in zeolite synthesis: cyclic and polycyclic N-heterocycles connected by methylene chains. J Am Chem Soc 131:1092-1100.

42. Shvets O, Kasian N, Zukal A et al (2010) The role of template structure and synergism between inorganic and organic structure directing agents in the synthesis of UTL zeolite. Chem Mater 22:3482-3495.

43. Davis ME (2014) Zeolites from a materials chemistry perspective. Chem Mater 26:239-245

44. Tsuji K, Beck LW, Davis ME (1999) Synthesis of 4,4'-trimethylenebis(1-benzyl-1methylpiperidinium) diastereomers and their use as structure-directing agents in puresilica molecular sieves syntheses. Microporous Mesoporous Mater 28:519-530. 
45. Lee G, Nakagawa Y, Hwang S et al (2002) Organocations in zeolite synthesis: fused bicyclo [1.m.0] cations and the discovery of zeolite SSZ-48. J Am Chem Soc 124:702434.

46. García R, Gómez-Hortigüela L, Sánchez F et al (2010) Diasteroselective structure directing effect of (1S,2S)-2-Hydroxymethyl-1-benzyl-1-methylpyrrolidinium in the synthesis of ZSM-12. Chem Mater 22:2276-2286.

47. Gallego EM, Portilla MT, Paris C (2017) "Ab initio" synthesis of zeolites for preestablished catalytic reactions. Science 355:1051-1054.

48. Burkett SL, Davis ME (1994) Mechanism of Structure Direction in the Synthesis of Si-ZSM-5: An Investigation by Intermolecular ${ }^{1} \mathrm{H}^{-29} \mathrm{Si} \mathrm{CP}$ MAS NMR. J Phys Chem 98:4647-4653.

49. Burkett SL, Davis ME (1995) Mechanisms of Structure Direction in the Synthesis of Pure-Silica Zeolites. 1. Synthesis of TPA/Si-ZSM-5. Chem Mater 7:920-928.

50. Burkett SL, Davis ME (1995) Mechanism of structure direction in the synthesis of pure-silica zeolites. 2. Hydrophobic hydration and structural specificity. Chem Mater 7:1453-1463.

51. Kubota Y, Helmkamp MM, Zones SI et al (1996) Properties of organic cations that lead to the structure-direction of high-silica molecular sieves. Microporous Mater 6 :213-229.

52. Jo C, Lee S, Cho SJ et al (2015) Synthesis of silicate zeolite analogues using organic sulfonium compounds as structure-directing agents. Angew Chem Int Ed 54:1280512808 .

53. Delprato F, Delmotte L, Guth JL et al (1990) Synthesis of new silica-rich cubic and hexagonal faujasites using crown-ether based supramolecules as templates. Zeolites 10:546-552.

54. Balkus KJ, Hargis CD, Kowalak S (1992) Synthesis of NaX zeolites with metallophthalocyanines. ACS Symp Ser 499:347-354

55. Dorset DL, Kennedy GJ, Strohmaier KG et al (2006) P-derived organic cations as structure-directing agents: Synthesis of a high-silica zeolite (ITQ-27) with a twodimensional 12-ring channel system. J Am Chem Soc 128:8862-8867.

56. Wan Y, Zhao D (2007) On the controllable soft-templating approach to mesoporous silicates. Chem Rev 107:2821-2860.

57. Moteki T, Keoh SH, Okubo T (2014) Synthesis of zeolites using highly amphiphilic cations as structure-directing agents by hydrothermal treatment of a dense silicate gel. Chem Commun 50:1330-1333.

58. Cho M, Na K, Kim J et al (2009) Stable single-unit-cell nanosheets of zeolite MFI as active and long-lived catalysts. Nature 461:246-249.

59. Kim W, Kim JC, Kim J et al (2013) External surface catalytic sites of surfactanttailored nanomorphic zeolites for benzene isopropylation to cumene. ACS Catal 3:192195.

60. Luo HY, Michaelis VK, Hodges S et al (2015) One-pot synthesis of MWW zeolite nanosheets using a rationally designed organic structure-directing agent. Chem Sci 6:6320-6324.

61. Seo Y, Lee S, Jo C et al (2013) Microporous aluminophosphate nanosheets and their nanomorphic zeolite analogues tailored by hierarchical structure-directing amines. J Am Chem Soc 135:8806-8809.

62. Corma A, Díaz-Cabañas MJ, Jorda JL et al (2008) A zeolitic structure (ITQ-34) with connected 9- and 10-ring channels obtained with phosphonium cations as structure directing agents. J Am Chem Soc 130:16482-16483. 
63. Villaescusa LA, Camblor MA (2016) Time evolution of an aluminogermanate zeolite synthesis: Segregation of two closely similar phases with the same structure type. Chem Mater 28: 3090-3098.

64. Caullet P, Guth JL, Hazm J et al (1991) Synthesis, characterization and crystalstructure of the new clathrasil phase octadecasil. Eur J Solid State Inorg Chem $28: 345-361$.

65. Villaescusa LA, Barrett PA, Camblor MA (1998) Calcination of octadecasil: Fluoride removal and symmetry of the pure $\mathrm{SiO}_{2}$ host. Chem Mater 10: 3966-3973.

66. Caullet P, Paillaud JL, Mathieu Y et al (2007) Synthesis of zeolites in the presence of diquaternary alkylammonium ions as structure-directing agents. Oil Gas Sci Technol 62:819-825.

67. Lee SH, Shin CH, Yang DK et al (2004) Reinvestigation into the synthesis of zeolites using diquaternary alkylammonium ions $\left(\mathrm{CH}_{3}\right)_{3} \mathrm{~N}^{+}\left(\mathrm{CH}_{2}\right)_{n} \mathrm{~N}^{+}\left(\mathrm{CH}_{3}\right)_{3}$ with $\mathrm{n}=3-10$ as structure-directing agents. Microporous Mesoporous Mater 68:97-104.

68. Rojas A, Camblor MA (2011) unpublished results.

69. Rojas A, Gómez-Hortigüela L, Camblor MA (2013) Benzylimidazolium cations as zeolite structure-directing agents. Differences in performance brought about by a small change in size. Dalton Trans 42: 2562-2571.

70. Parnham ER, Morris RE (2006) 1-Alkyl-3-methyl Imidazolium bromide ionic liquids in the ionothermal synthesis of aluminium phosphate molecular sieves. Chem Mater 18:4882-4887.

71. Gómez-Hortigüela L, Gálvez P, unpublished results.

72. Parnham ER, Drylie EA, Wheatley PS et al (2006) Ionothermal materials synthesis using unstable deep-eutectic solvents as template-delivery agents. Angew Chem 118:2084-5088.

73. Lee H, Zones SI, Davis ME (2003) A combustion-free methodology for synthesizing zeolites and zeolite-like materials. Nature 425:385-388.

74. Lee H, Zones SI, Davis ME (2005) Zeolite synthesis using degradable structuredirecting agents and pore-filling agents. J Phys Chem B 109:2187-2191.

75. Lee H, Zones SI, Davis ME (2006) Synthesis of molecular sieves using ketal structure-directing agents and their degradation inside the pore space. Microporous Mesoporous Mater 88:266-274.

76. Takekiyo T, Yoshimura Y (2006) Raman Spectroscopic Study on the Hydration Structures of Tetraethylammonium Cation in Water. J Phys Chem A 110:10829-10833.

77. O'Brien MG, Beale AM, Catlow CRA et al (2006) Unique organic-inorganic interactions leading to a structure-directed microporous aluminophosphate crystallization as observed with in situ Raman spectroscopy. J Am Chem Soc 128:11744-11745.

78. Schmidt JE, Fu D, Deem MW et al (2016) Template-framework interactions in tetraethylammonium-directed zeolite synthesis. Angew Chem Int Ed 55:16044-16048.

79. Sánchez-Sánchez M, Sankar G, Gómez-Hortigüela L (2008) NMR evidence of different conformations of structure-directing cyclohexylamine in high-doped $\mathrm{AlPO}_{4}-44$ materials. Microporous Mesoporous Mater 114:485-494.

80. Hong SB, Min HK, Shin CH et al (2007) Synthesis, crystal structure, characterization, and catalytic properties of TNU-9. J Am Chem Soc 129:10870-10885.

81. Gramm F, Baerlocher C, McCusker LB et al (2006) Complex zeolite structure solved by combining powder diffraction and electron microscopy. Nature 444:79-81.

82. Hong SB, Lear EG, Wright PA et al (2004) Synthesis, structure solution, characterization, and catalytic properties of TNU-10: A high-silica zeolite with the STI topology. J Am Chem Soc 126:5817-5826. 
83. Bernardo-Maestro B, López-Arbeloa F, Pérez-Pariente J et al (2015) Supramolecular chemistry controlled by conformational space during structure-direction of nanoporous materials: self-assembly of ephedrine and pseudoephedrine. J Phys Chem C 119:2821428225.

84. Bernardo-Maestro B, López-Arbeloa F, Pérez-Pariente J et al (2017) Comparison of the structure-directing effect of ephedrine and pseudoephedrine during crystallization of nanoporous aluminophosphates. Microporous Mesoporous Mater in press; https://doi.org/10.1016/j.micromeso.2017.04.008.

85. Camblor MA, Hong SB (2011) Synthetic silicate zeolites: Diverse materials accessible through geoinspiration, Chapter 5 in Porous Materials, Bruce DW, O'Hare D, Walton IR (eds) Wiley, Chichester (UK).

86. Flanigen EM, Patton RL (1978) US Patent 4,073,865.

87. Guth JL, Kessler K, Higel JM et al (1989) Zeolite synthesis in the presence of fluoride ions. ACS Symp Ser 398:176-195.

88. Guth J, Kessler H, Caullet P et al (1993) $\mathrm{F}^{-}$: A multifunctional tool for microporous solids a) mineralizing, structure directing and templating effects in the synthesis. In: von Ballmoos R, Higgins J, Treacy M, editors. Proc of the 9th International Zeolite Conf London, pp 215-222.

89. Caullet P, Paillaud JL, Simon-Masseron A et al (2005) The fluoride route: A strategy to crystalline porous material. C R Chimie 8:245-266.

90 Koller H, Lobo RF, Burkett SL et al (1995) $\mathrm{SiO}^{-} \cdots$ HOSi hydrogen bonds in assynthesized high-silica zeolites. J Phys Chem 99:12588-12596.

91. Blasco T, Camblor MA, Corma A et al (1998) Direct synthesis and characterization of hydrophobic aluminum-free Ti-Beta zeolite. J Phys Chem 102:75-88.

92. Camblor MA, Corma A, Iborra S et al (1997) Beta zeolite as a catalyst for the preparation of alkyl glucoside surfactants: The role of crystal size and hydrophobicity. $\mathrm{J}$ Catal 172:76-84.

93. Eroshenko V, Regis RC, Soulard M et al (2001) Energetics: A new field of applications for hydrophobic zeolites. J Am Chem Soc 123: 8129-8130.

94. Villaescusa LA, Camblor MA (2003) The fluoride route to new zeolites. Recent Res Devel Chem 1:93-141.

95. Zicovich-Wilson CM, San-Román ML, Camblor MA et al. (2007) Structure, vibrational analysis, and insights into host-guest interactions in as-synthesized pure silica ITQ-12 zeolite by periodic B3LYP calculations. J Am Chem Soc 129:11512-11523.

96. Zicovich-Wilson CM, Gándara F, Monge A et al (2010) In situ transformation of TON silica zeolite into the less dense ITW: Structure-direction overcoming framework instability in the synthesis of $\mathrm{SiO}_{2}$ zeolites. J Am Chem Soc 132:3461-3471.

97. Camblor MA, Villaescusa LA, Díaz-Cabañas MJ (1999) Synthesis of all-silica and high-silica molecular sieves in fluoride. Top Catal 9:59-76.

98. Camblor MA, Barrett PA, Díaz-Cabañas MJ et al (2001) High silica zeolites with three-dimensional systems of large pore channels. Microporous Mesoporous Mater 48:11-22.

99. Zones SI, Darton RJ, Morris R et al (2005) Studies on the role of fluoride ion vs reaction concentration in zeolite synthesis. J Phys Chem B 109:652-661.

100. Burton AW, Lee GS, Zones SI (2006) Phase selectivity in the syntheses of cagebased zeolite structures: An investigation of thermodynamic interactions between zeolite hosts and structure directing agents by molecular modeling. Microporous Mesoporous Mater 90:129-144. 
101. Zones SI, Hwang SJ, Elomari S et al (2005) The fluoride-based route to all-silica molecular sieves; a strategy for synthesis of new materials based upon close-packing of guest-host products. C R Chimie 8:267-282.

102. Camblor MA, Díaz-Cabañas MJ, Cox PA et al (1999) A Synthesis, MAS NMR, Synchrotron X-ray Powder Diffraction, and Computational Study of Zeolite SSZ-23. Chem Mater 11: 2878-2885.

103. Lobo RF, Zones SI, Davis ME (1995) Structure-direction in zeolite synthesis. J Incl Phenom Macro 21:47-78.

104. Catlow CRA, Coombes DS, Lewis D et al (1998) Computer modeling of nucleation, growth, and templating in hydrothermal synthesis. Chem Mater 10:3249-3265.

105. Jorge M, Auerbach SM, Monson PA (2005) Modeling spontaneous formation of precursor nanoparticles in clear-solution zeolite synthesis. J Am Chem Soc 127:1438814400.

106. Piccione P, Yang S, Navrotsky A et al (2002) Thermodynamics of pure-silica molecular sieve synthesis. J Phys Chem B 106:3629-38.

107. Piccione P, Woodfield B, Boerio-Goates J et al (2001) Entropy of pure-silica molecular sieves. J Phys Chem B 105(25):6025-30.

108. Khan MN, Auerbach SM, Monson PA (2015) Lattice Monte Carlo simulations in search of zeolite analogues: effects of structure directing agents. J Phys Chem C 119:28046-28054.

109. Yu J, Xu R (2003) Rich structure chemistry in the aluminophosphate family. Acc Chem Res 36:481-490.

110. Lewis DW, Freeman CM, Catlow CRA (1995) Predicting the templating ability of organic additives for the synthesis of microporous materials. J Phys Chem 99:1119411202 .

111. Lewis DW, Willock DJ, Catlow CRA et al (1996) De novo design of structuredirecting agents for the synthesis of microporous solids. Nature 382:604-606.

112. Schmidt JE, Deem MW, Davis ME (2014) Synthesis of a specified, silica molecular sieve using computationally predicted organic structure-directing agents. Angew Chem Int Ed 126:8512-8514.

113. Brunklaus G, Koller H, Zones SI (2016) Defect models of as-made high-silica zeolites: Clusters of hydrogen-bonds and their interaction with the organic structuredirecting agents determined from ${ }^{1} \mathrm{H}$ Double and Triple Quantum NMR Spectroscopy. Angew Chem Int Ed 55:14459-14463.

114. Dib E, Grand J, Mintova S et al (2015) Structure-directing agent governs the location of silanol defects in zeolites. Chem Mater 27:7577-7579.

115. Gómez-Hortigüela L, Pinar AB, Corà F et al (2010) Dopant-siting selectivity in nanoporous catalysts: control of proton accessibility in zeolite catalysts through the rational use of templates. Chem Commun 46:2073-2075.

116. Román-Leshkov Y, Moliner M, Davis ME (2011) Impact of controlling the site distribution of al atoms on catalytic properties in ferrierite-type zeolites. J Phys Chem C 115:1096-1102.

117. Yokoi T, Mochizuki H, Namba S et al (2015) Control of the Al Distribution in the Framework of ZSM-5 Zeolite and Its Evaluation by Solid-State NMR Technique and Catalytic Properties. J Phys Chem C 119:15303-15315.

118. Gómez-Hortigüela L, Álvaro-Muñoz T, Bernardo-Maestro B et al (2015) Towards chiral distributions of dopants in microporous frameworks: helicoidal supramolecular arrangement of (1R,2S)-ephedrine and transfer of chirality. Phys Chem Chem Phys $17: 348-357$ 
119. Lemishko T, Simancas J, Hernández-Rodríguez M et al (2016) An INS study of entrapped organic cations within the micropores of zeolite RTH. Phys Chem Chem Phys 18:17244-17252.

120. Gómez-Hortigüela L, Hamad S, Pinar AB et al (2009) Molecular insights into the self-aggregation of aromatic molecules in the synthesis of nanoporous aluminophosphates: a multilevel approach. J Am Chem Soc 131:16509-16524.

121. Wang Y, Yu J, Li Y et al (2003) Chirality transfer from guest chiral metal complexes to inorganic framework: The role of hydrogen bonding. Chem Eur J 9:5048-5055.

122. Behrens P, van de Goor G, Freyhardt CC (1995) Structure-determining C-H $\cdots$ O-Si hydrogen bonds in cobaltocenium fluoride nonasil. Angew Chem Int Ed 34: 2680-2682.

123. Lee JK, Shin J, Ahn NH et al (2015) A family of molecular sieves containing framework-bound organic structure-directing agents. Angew Chem Int Ed 54:1109711101.

124. Lee JK, Lee JH, Ahn NH et al (2016) Solid solution of a zeolite and a frameworkbound OSDA-containing molecular sieve. Chem Sci 7:5805-5814.

125. Gómez-Hortigüela L, López-Arbeloa F, Corà F et al (2008) Supramolecular chemistry in the structure direction of microporous materials from aromatic structure-directing agents. J Am Chem Soc 130:13274-13284.

126. Corma A, Rey F, Rius J et al (2004) Supramolecular self-assembled molecules as organic directing agent for synthesis of zeolites. Nature 431:287-290.

127. Moliner M (2015) Design of zeolites with specific architectures using selfassembled aromatic organic structure-directing agents. Top Catal 25:502-512.

128. Corma A, Díaz-Cabañas MJ, Jordá JL et al (2006) High-throughput synthesis and catalytic properties of a molecular sieve with 18 - and 10-member rings. Nature 443:842-845

129. Welton T (1999) Room-temperature ionic liquids. Solvents for synthesis and catalysis. Chem Rev 99:2071-2083.

130. Arduengo AJ, Harlow RL, Kline M (1991) A stable crystalline carbene. J Am Chem Soc 113:361-363.

131. Zones SI (1989) Synthesis of pentasil zeolites from sodium silicate solutions in the presence of quaternary imidazole compounds. Zeolites 9:458-467.

132. Barrett PA, Boix T, Puche M et al (2003) ITQ-12: A new microporous silica polymorph potentially useful for light hydrocarbon separations. Chem Commun 2114-2115.

133. Parnham ER, Morris RE (2006) The ionothermal synthesis of cobalt aluminophosphate zeolite frameworks. J Am Chem Soc 128: 2204-2205.

134. Lorgouilloux Y, Dodin M, Paillaud JL et al (2009) IM-16: A new microporous germanosilicate with a novel framework topology containing D4R and MTW composite building units. J Solid State Chem 182:622-629.

135. Dodin M, Paillaud JL, Lorgouilloux Y et al (2010) A zeolitic material with a threedimensional pore system formed by straight 12- and 10-ring channels synthesized with an imidazolium derivative as structure-directing agent. J Am Chem Soc 132:1022110223.

136. Schmidt JE, Xie D, Rea T et al (2015) CIT-7, a crystalline, molecular sieve with pores bounded by 8 and 10-membered rings. Chem Sci 6:1728-1734.

137. Boal BW, Deem MW, Xie D et al (2016) Synthesis of germanosilicate molecular sieves from mono- and di-quaternary ammonium OSDAs constructed from benzyl imidazolium derivatives: Stabilization of large micropore volumes including new molecular sieve CIT-13. Chem Mater 28:2158-2164. 
138. Olson DH, Yang X, Camblor MA (2004) ITQ-12: A zeolite having temperature dependent adsorption selectivity and potential for propene separation. J Am Chem Soc 108:11044-11048.

139. Rojas A, Martínez-Morales A, Zicovich-Wilson CM, Camblor MA (2012) Zeolite synthesis in fluoride media: Structure direction toward ITW by small methylimidazolium cations. J Am Chem Soc 134:2255-2263.

140. Rojas A, San-Roman ML, Zicovich-Wilson CM et al (2013) Host-guest stabilization of a zeolite strained framework: In situ transformation of zeolite MTW into the less dense and more strained ITW. Chem Mater 25:729-738.

141. Rojas A, Camblor MA (2012) A pure silica chiral polymorph with helical pores. Angew Chem Int Ed 51:3854-3856

142. Rojas A, Camblor MA (2014) HPM-2, the layered precursor to zeolite MTF. Chem Mater 26:1161-1169.

143. Rojas A, Camblor MA (2014) Structure-direction in the crystallization of ITW zeolites using 2-ethyl-1,3,4-trimethylimidazolium. Dalton Trans 43:10760-10766.

144. Rojas AE (2012) Dirección de estructuras en la síntesis de zeolitas usando cationes orgánicos imidazolios. PhD Thesis. Universidad Autónoma de Madrid.

145. Cooper ER, Andrews CD, Wheatley PS et al (2004) Ionic liquids and eutectic mixtures as solvent and template in synthesis of zeolite analogues. Nature 430:1012-1016.

146. Parnham ER, Morris RE (2007) Ionothermal synthesis of zeolites, metal-organic frameworks, and inorganic-organic hybrids. Acc Chem Res 40:1005-1013.

147. Parnham ER (2006) Ionothermal synthesis. A new synthesis methodology using ionic liquids and eutectic mixtures as both solvent and template in zeotype synthesis. $\mathrm{PhD}$ Thesis. University of St. Andrews.

148. Wagner P, Yoshikawa M, Lovallo M et al (1997) CIT-5: A high-silica zeolite with 14-ring pores. Chem Commun 2179-2180.

149. Kang JH, Xie D, Zones SI et al (2016) Synthesis and characterization of CIT-13, a germanosilicate molecular sieve with extra-large pore openings. Chem Mater 28: 62506259.

150. Tang L, Shi L, Bonneau C et al (2008) A zeolite family with chiral and achiral structures built from the same building layer. Nat Mater 7:381-385.

151. Kapko V, Dawson C, Treacy MMJ et al (2010) Flexibility of ideal zeolite frameworks. Phys Chem Chem Phys 12: 8531-8541.

152. Sastre G, Corma A (2010) Predicting structural feasibility of silica and germania zeolites. J Phys Chem C 114:1667-1673.

153. Sartbaeva A, Wells SA, Treacy MMJ et al (2006) The flexibility window in zeolites. Nat Mater 5:962-965.

154. Medina ME, Platero-Prats AE, Snejko N et al (2011) Towards inorganic porous materials by design: Looking for new architectures. Adv Mater 23: 5283-5292.

155. Rojas A, Arteaga O, Kahr B et al (2013) Synthesis, structure and optical activity of HPM-1, a pure silica chiral zeolite. J Am Chem Soc 135:11975-11984.

156. Jo D, Hong SB, Camblor MA (2015) Monomolecular skeletal isomerization of 1butene over selective zeolite catalysts. ACS Catal 5: 2270-2274.

157. Pophale R, Daeyaert F, Deem MW (2013) Computational prediction of chemically synthesizable organic structure directing agents for zeolites. J Mat Chem A 1:67506760.

158. Schmidt JE, Deimund MA, Davis ME (2014) Facile preparation of aluminosilicate RTH across a wide composition range using a new organic structure-directing agent. Chem Mater 26:7099-7105. 
159. Schmidt JE, Deimund ME, Xie D et al (2015) Synthesis of RTH-type zeolites using a diverse library of imidazolium cations. Chem Mater 27: 3756-3762.

160. Jo D, Lim JB, Ryu T et al (2015) Unseeded hydroxide-mediated synthesis and $\mathrm{CO}_{2}$ adsorption properties of an aluminosilicate zeolite with the RTH topology. J Mater Chem A 3:19322-19329.

161. Schmidt JE, Xie D, Davis ME (2015) Synthesis of the RTH-type layer: the first small-pore, two dimensional layered zeolite precursor. Chem Sci 6: 5955-5963.

162. Brand SK, Schmidt JE, Deem MW et al (2017) Enantiomerically enriched, polycrystalline molecular sieves. P Natl Acad Sci USA 114:5101-5106. 